\title{
Reductive 3-Silylation of Benzofuran Derivatives via Coupling Reaction with Chlorotrialkylsilane
}

Suhua Zheng, Tianyuan Zhang, and Hirofumi Maekawa

Department of Materials Science and Technology, Nagaoka University of Technology, 1603-1, Kamitomiokacho, Nagaoka, Niigata 940-2188, Japan

\section{Table of Content}

Table S1 Optimization on the equivalents of Mg and chlorotrimethylsilane $\quad$ S2

$\begin{array}{ll}\text { Table S2 Study on the oxidation conditions } & \text { S3 }\end{array}$

$\begin{array}{ll}\text { Table S3 Reduction potential of substrates } & \text { S4 }\end{array}$

$\begin{array}{ll}\text { NMR spectra } & \text { S5 }\end{array}$ 
Table S1 Optimization on the equivalents of Mg and chlorotrimethylsilane

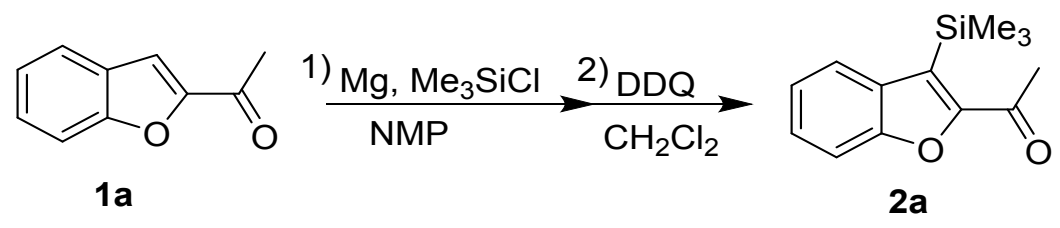

\begin{tabular}{cccc}
\hline Entry & $\mathrm{Me}_{3} \mathrm{SiCl}$ (equiv) & $\mathrm{Mg}$ (equiv) & GC Yield (\%) \\
\hline 1 & 5 & 4 & 39 \\
2 & 6 & 4 & 60 \\
3 & 7 & 4 & 47 \\
4 & 6 & 3 & 43 \\
5 & 6 & 5 & 34 \\
\hline
\end{tabular}

Reaction Conditions: 1) 1a (2 mmol), NMP (15 mL), $0{ }^{\circ} \mathrm{C}, 3 \mathrm{~h}, \mathrm{~N}_{2}$ atmosphere. 2) DDQ (1 equiv), $\mathrm{CH}_{2} \mathrm{Cl}_{2}(2$ $\mathrm{mL}), 25^{\circ} \mathrm{C}, 6 \mathrm{~h}$. Yields were determined by gas chromatography using $n$-undecane as the internal standard. 
Table S2 Study on the oxidation conditions

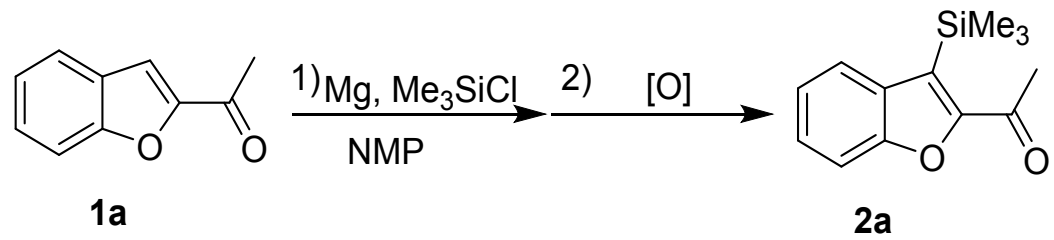

\begin{tabular}{ccccc}
\hline Entry & Oxidant (equiv) & Solvent $(\mathrm{mL})$ & $\begin{array}{c}\text { Oxidant } \\
\text { Concentration (M) }\end{array}$ & GC Yield (\%) \\
\hline 1 & DDQ (1.0) & $\mathrm{CH}_{2} \mathrm{Cl}_{2}(5)$ & 0.4 & 48 \\
2 & DDQ (0.8) & $\mathrm{CH}_{2} \mathrm{Cl}_{2}(2)$ & 0.8 & 39 \\
3 & DDQ (1.0) & $\mathrm{CH}_{2} \mathrm{Cl}_{2}(2)$ & 1.0 & 60 \\
4 & DDQ (1.0) & $\mathrm{CH}_{2} \mathrm{Cl}_{2}(1)$ & 2.0 & 42 \\
5 & DDQ (1.5) & $\mathrm{CH}_{2} \mathrm{Cl}_{2}(2)$ & 2.3 & 27 \\
6 & Air & - & - & 25 \\
7 [a]. & $\mathrm{H}_{2} \mathrm{O}_{2}$ & $\mathrm{THF}(5)$ & 2.4 & trace
\end{tabular}

Reaction Conditions: 1) 1a (2 mmol), $\mathrm{Mg}$ (4 equiv), $\mathrm{TMSCl}$ ( 6 equiv), NMP $(15 \mathrm{~mL}), 0{ }^{\circ} \mathrm{C}, 3 \mathrm{~h}, \mathrm{~N}_{2}$ atmosphere.

2) $25^{\circ} \mathrm{C}, 6 \mathrm{~h}$. GC yields were determined using $n$-undecane as the internal standard. [a]. $30 \% \mathrm{H}_{2} \mathrm{O}_{2}(1.5 \mathrm{~mL})$. 
Table S3 Reduction potential of substrates

$\begin{gathered}\text { Reduction Potential } \\ (\mathrm{V} \text { vs. Ag/AgCl) }\end{gathered}$
Entry

Working electrode: Pt, counter electrode: Pt, reference electrode: $\mathrm{Ag} / \mathrm{AgCl}$, solvent: NMP, supporting electrolyte: $1 \% n \mathrm{Bu}_{4} \mathrm{NClO}_{4}$, scan rate: $0.2 \mathrm{Vs}^{-1}$ 


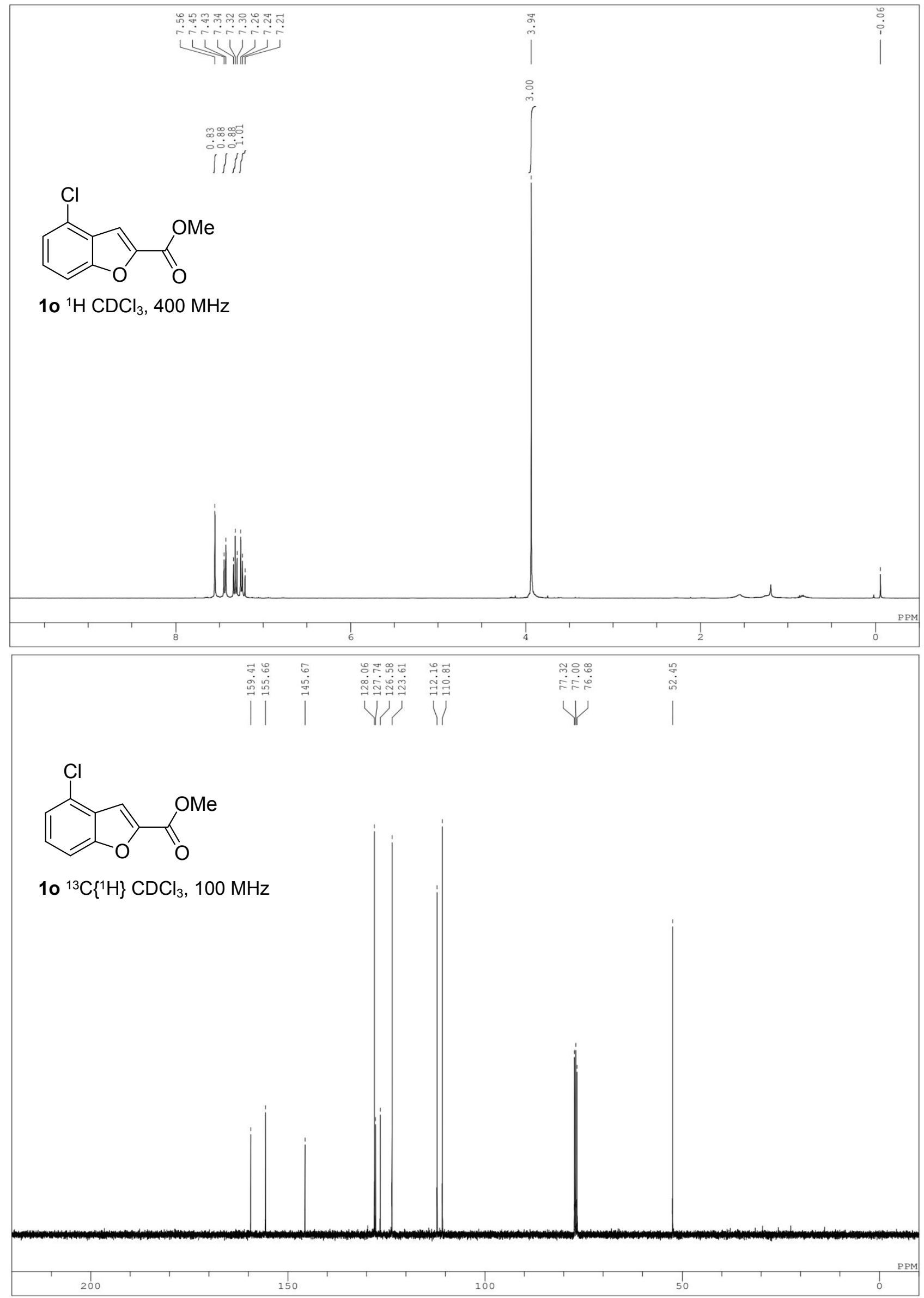




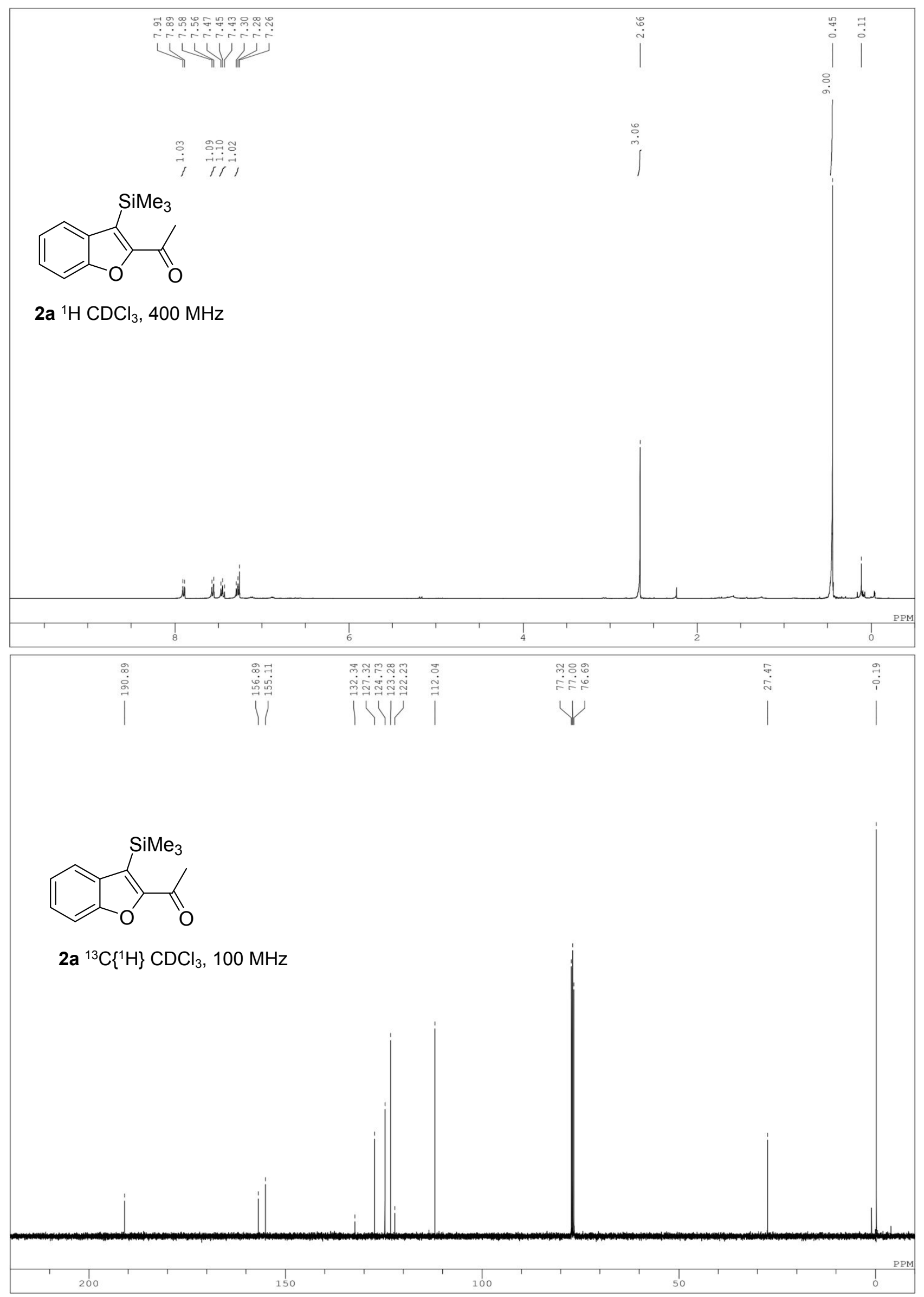

S6 


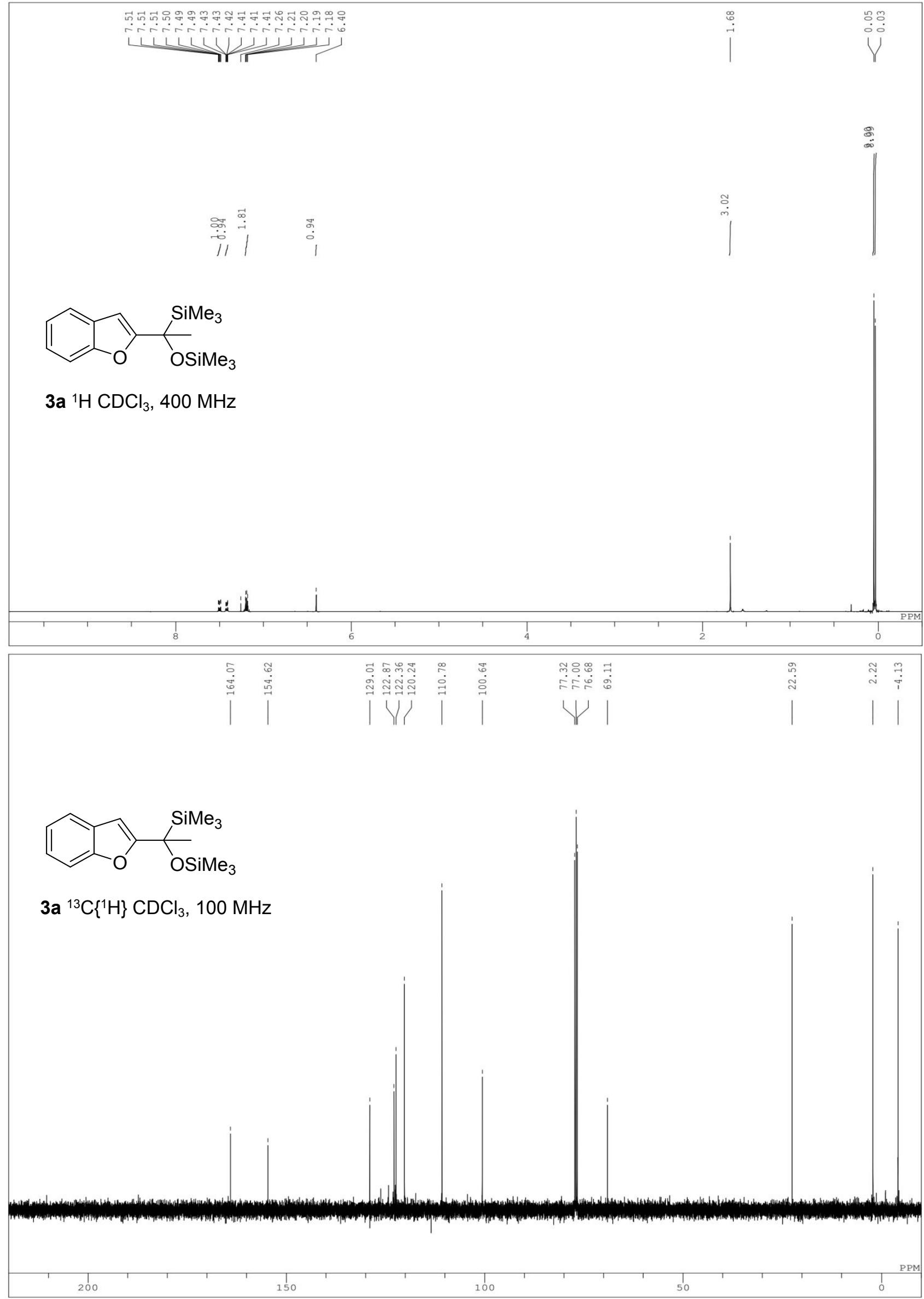




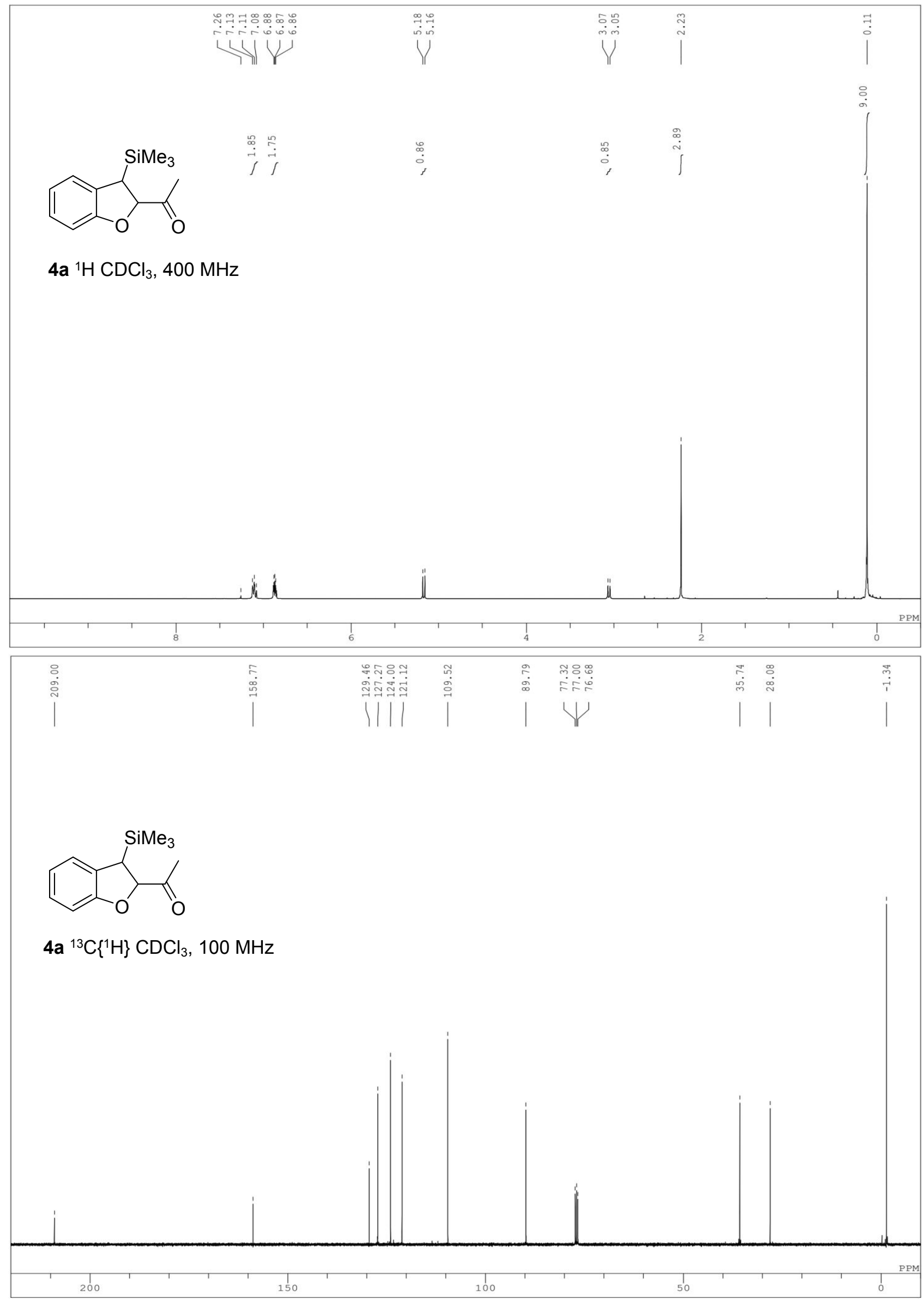




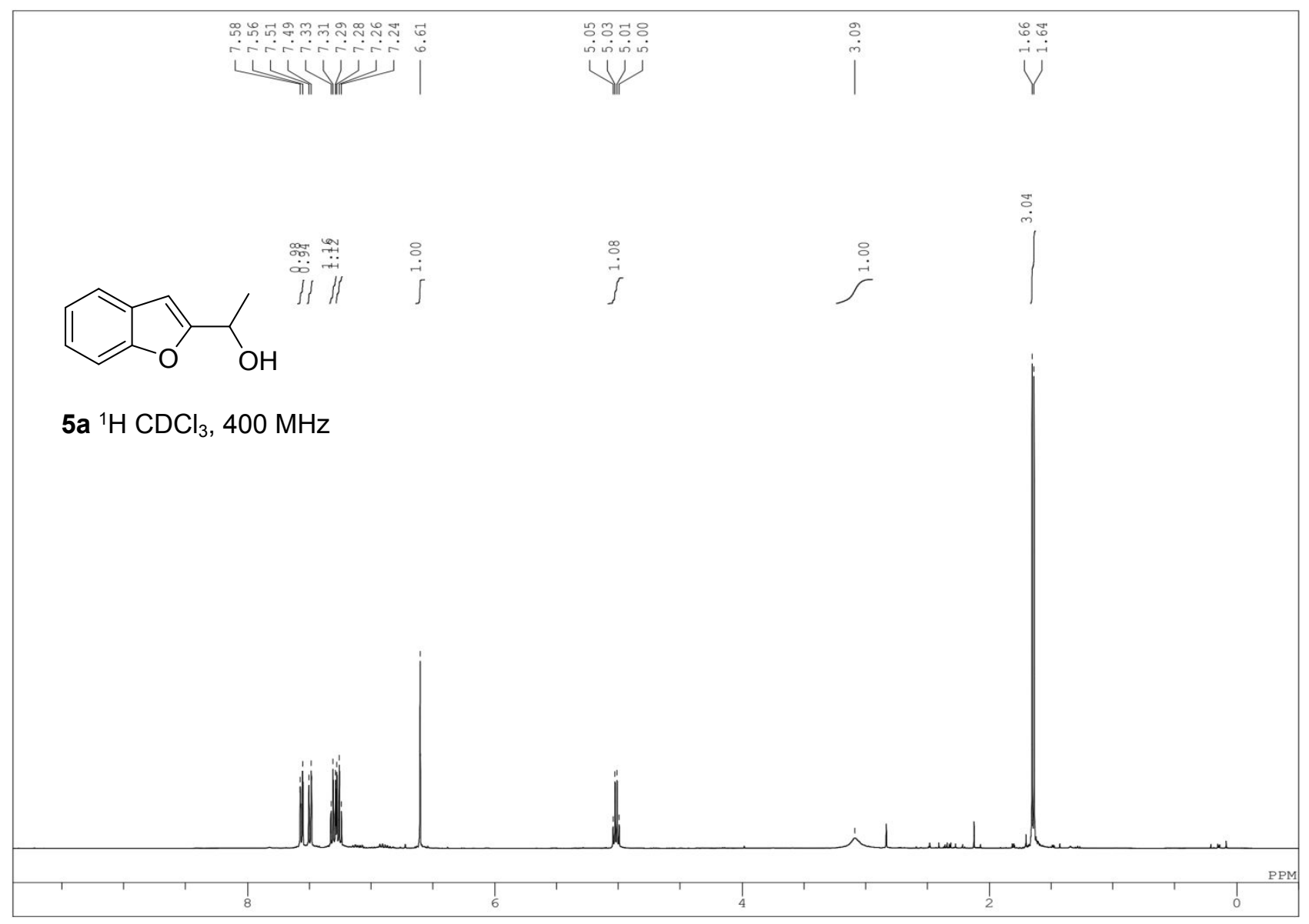

S9 


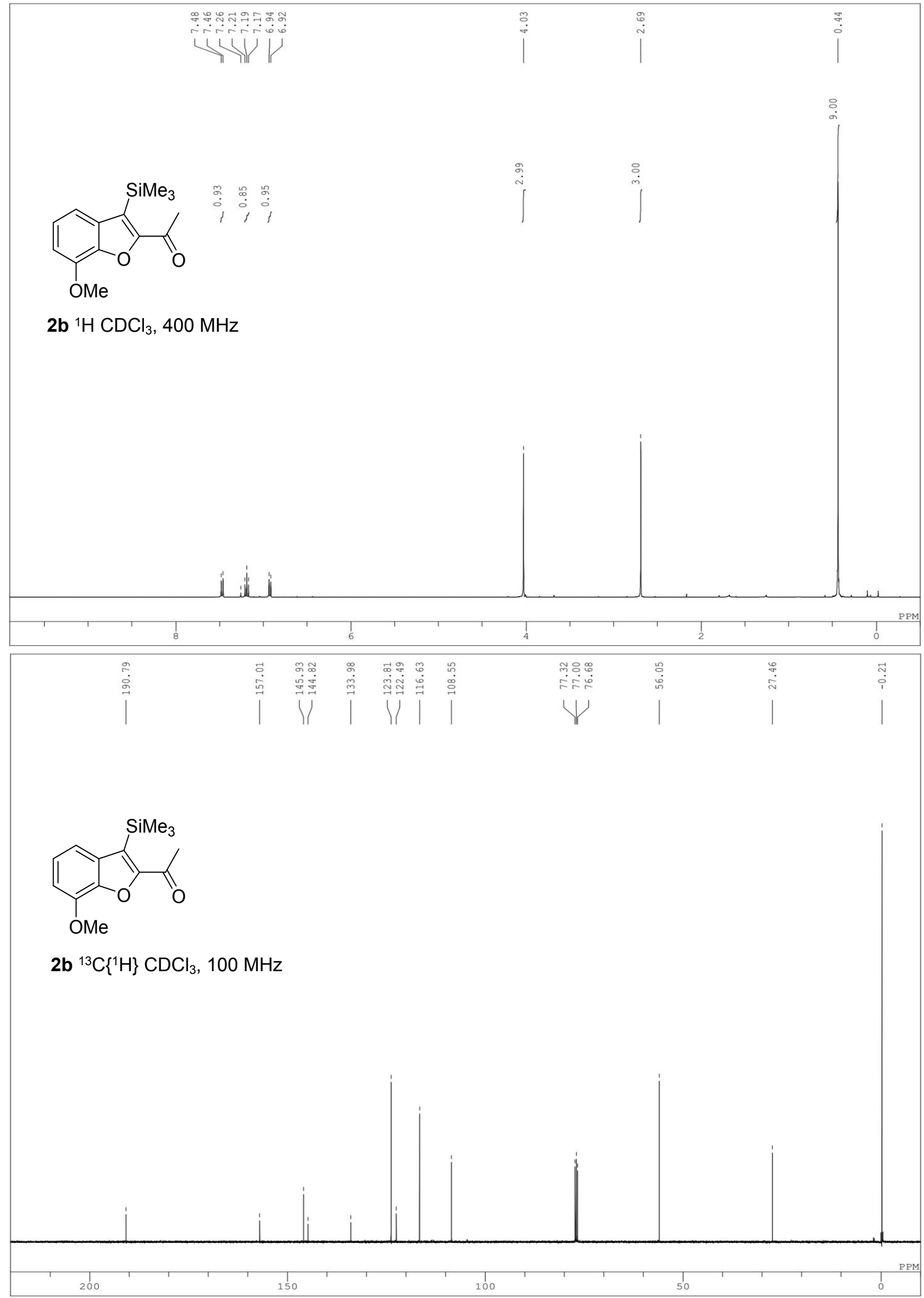




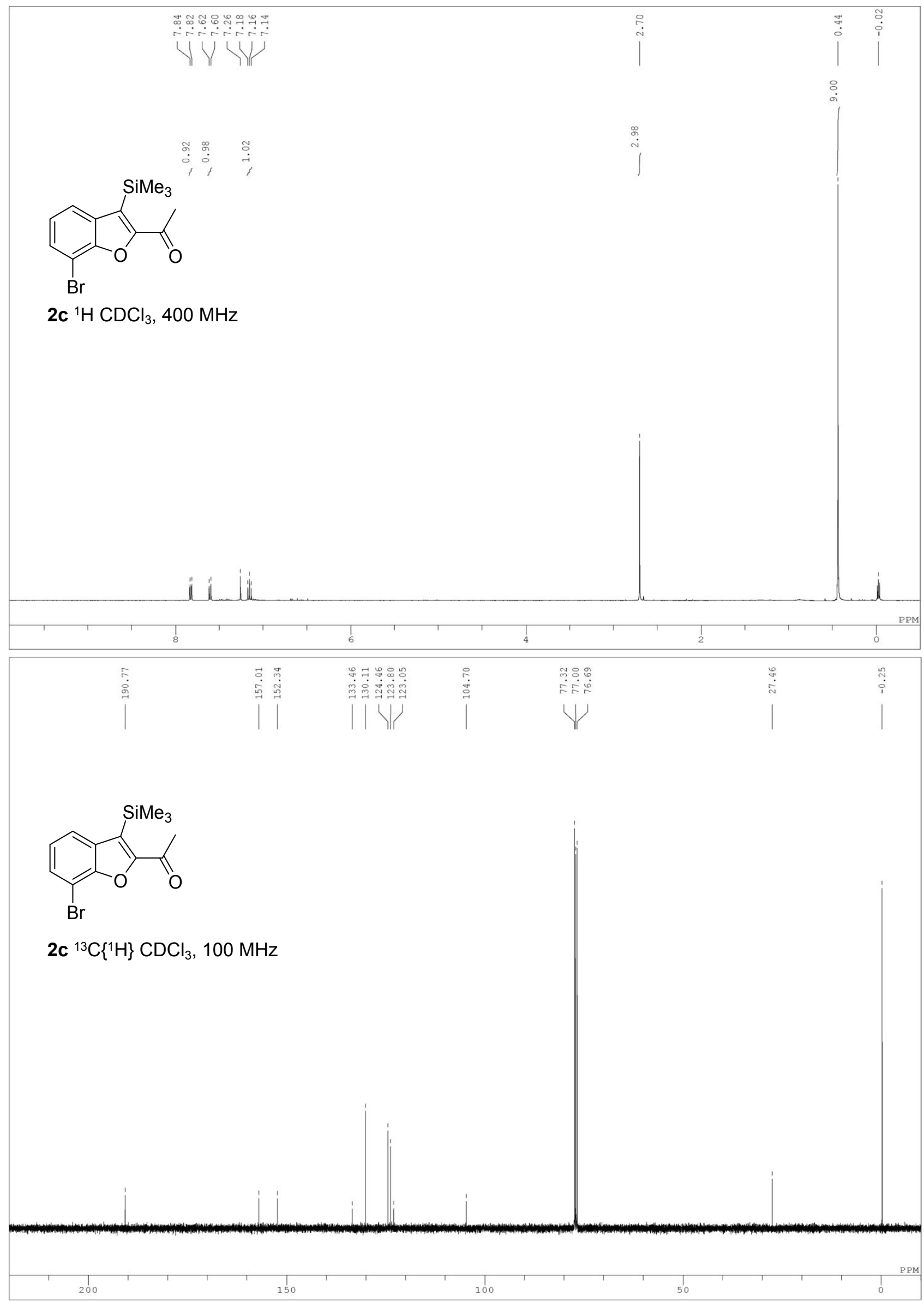




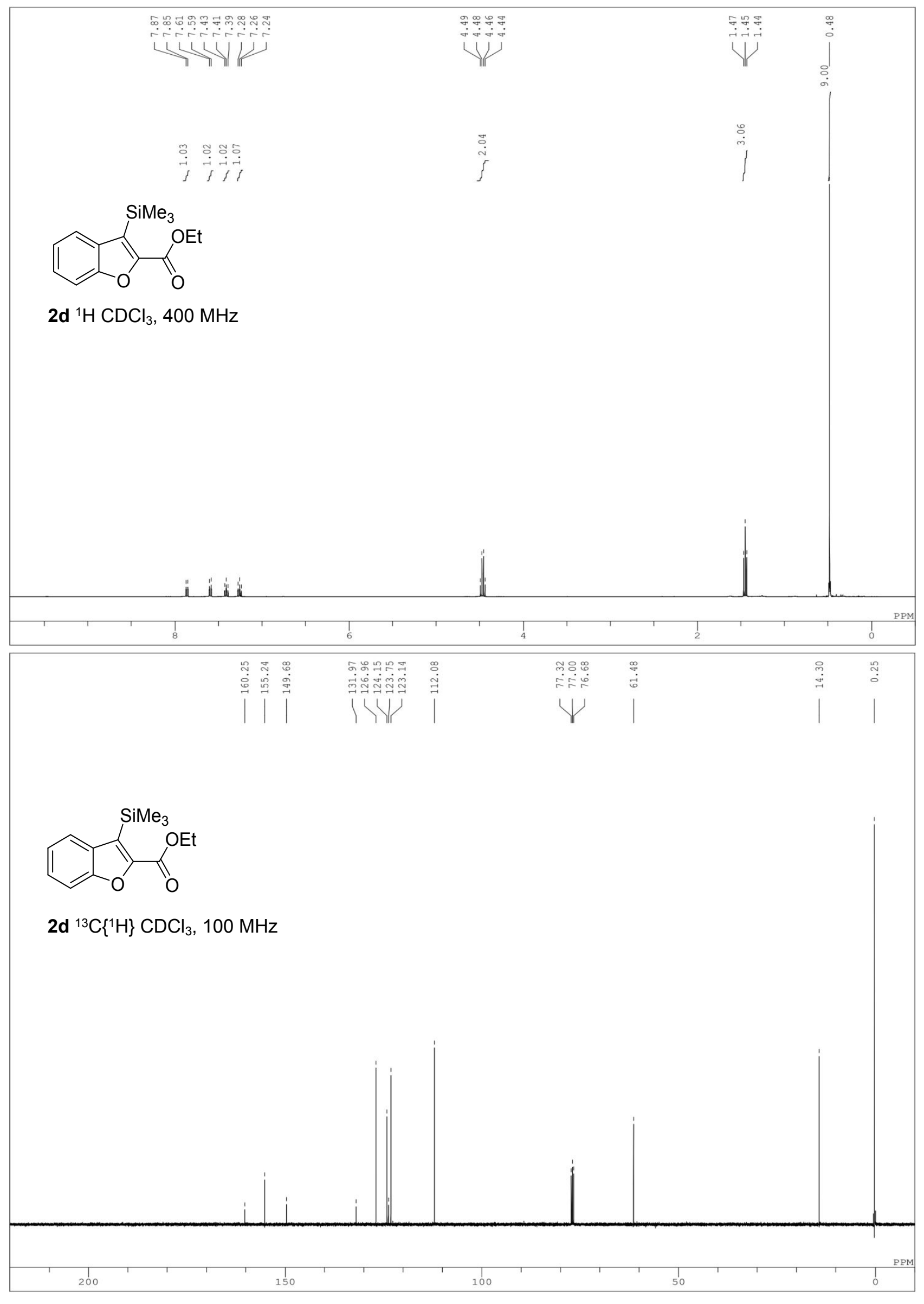

S12 


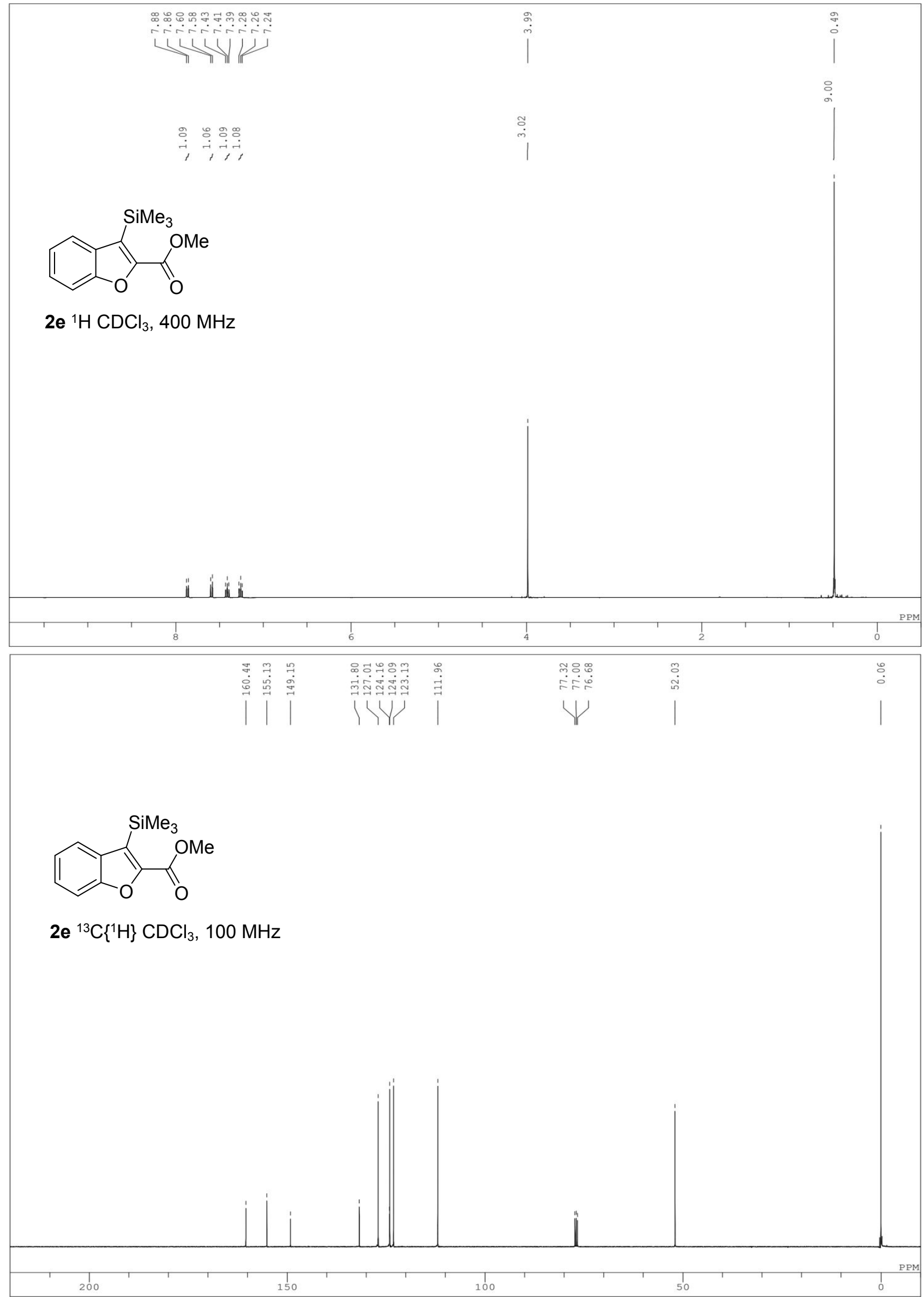




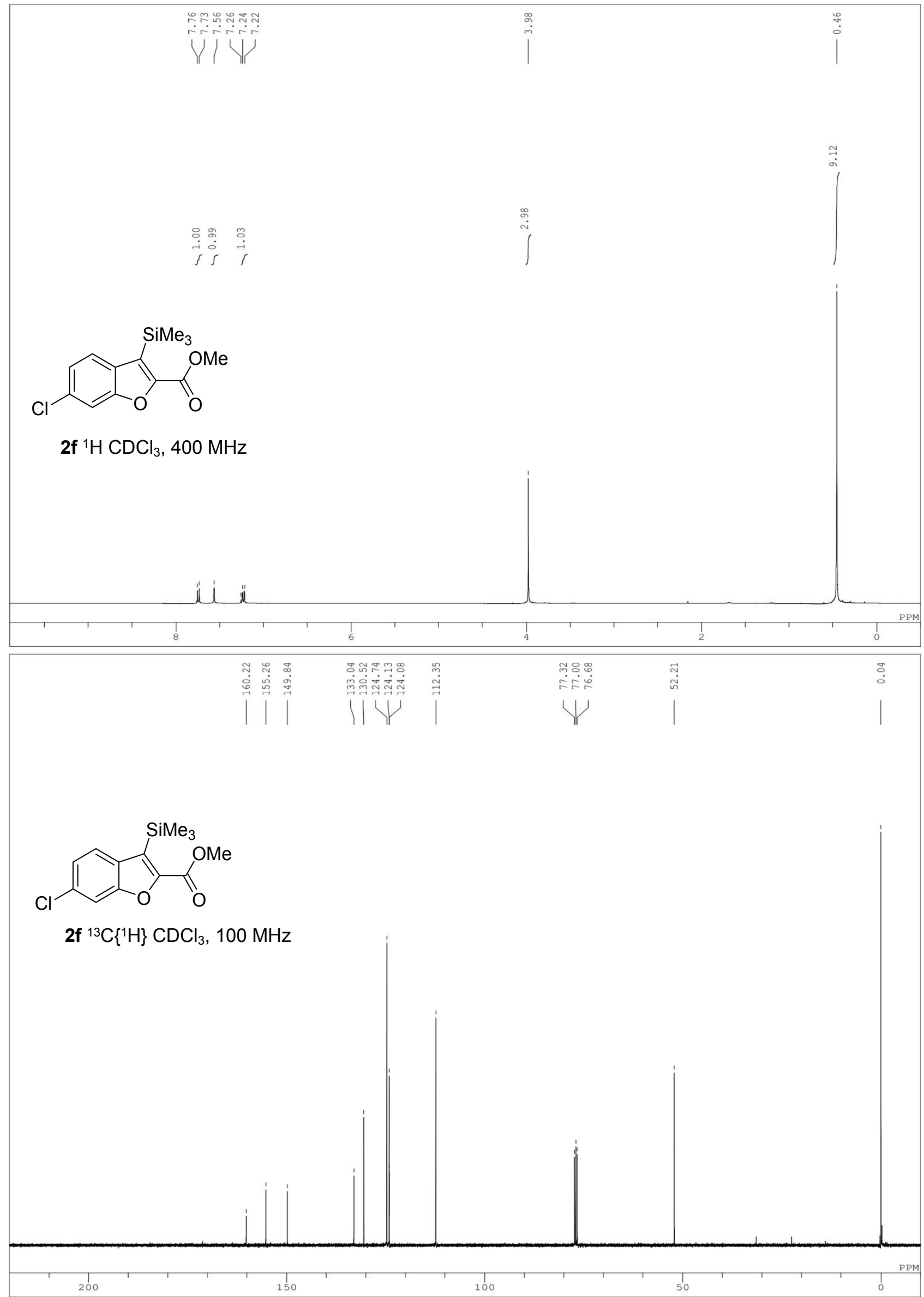




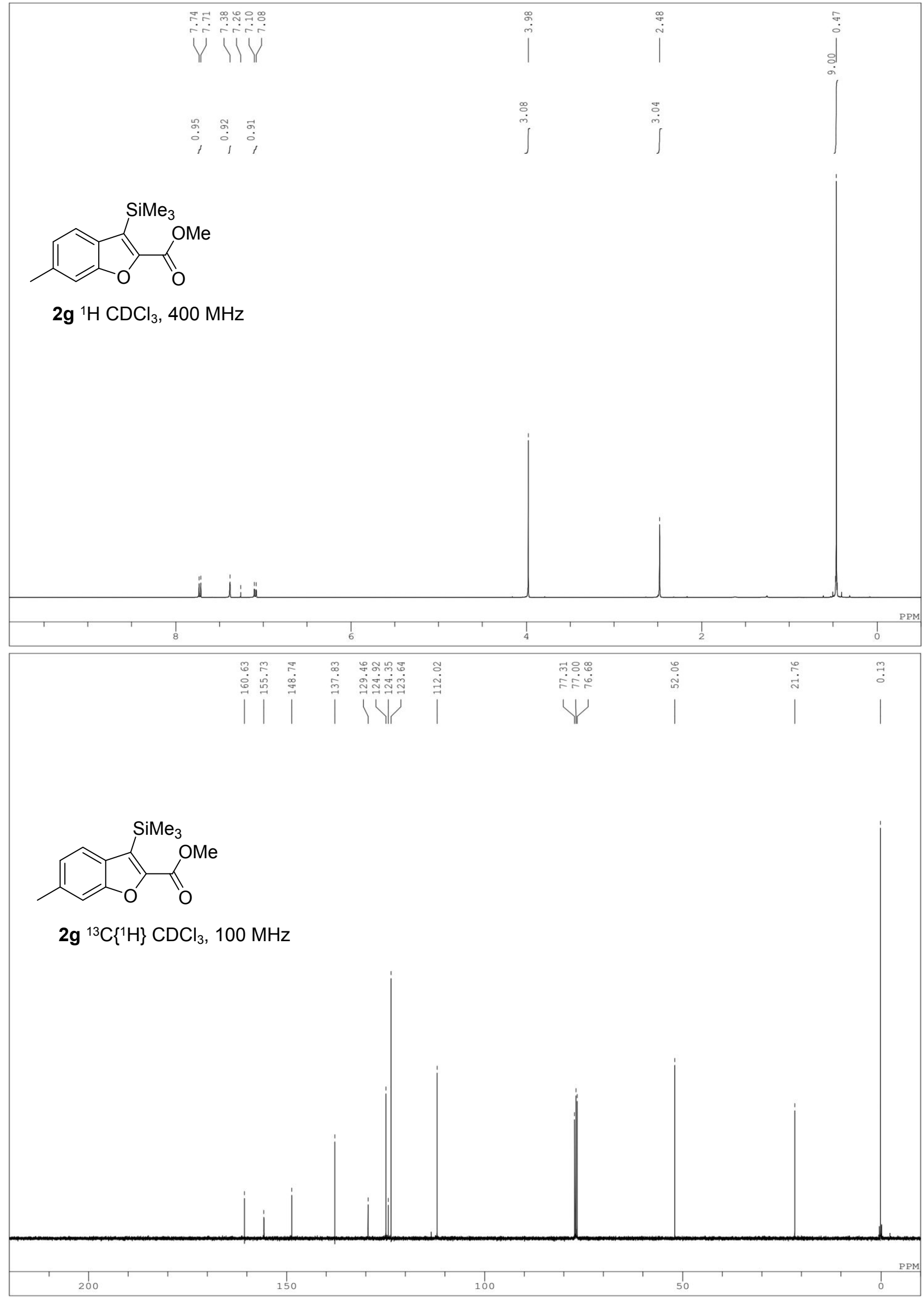




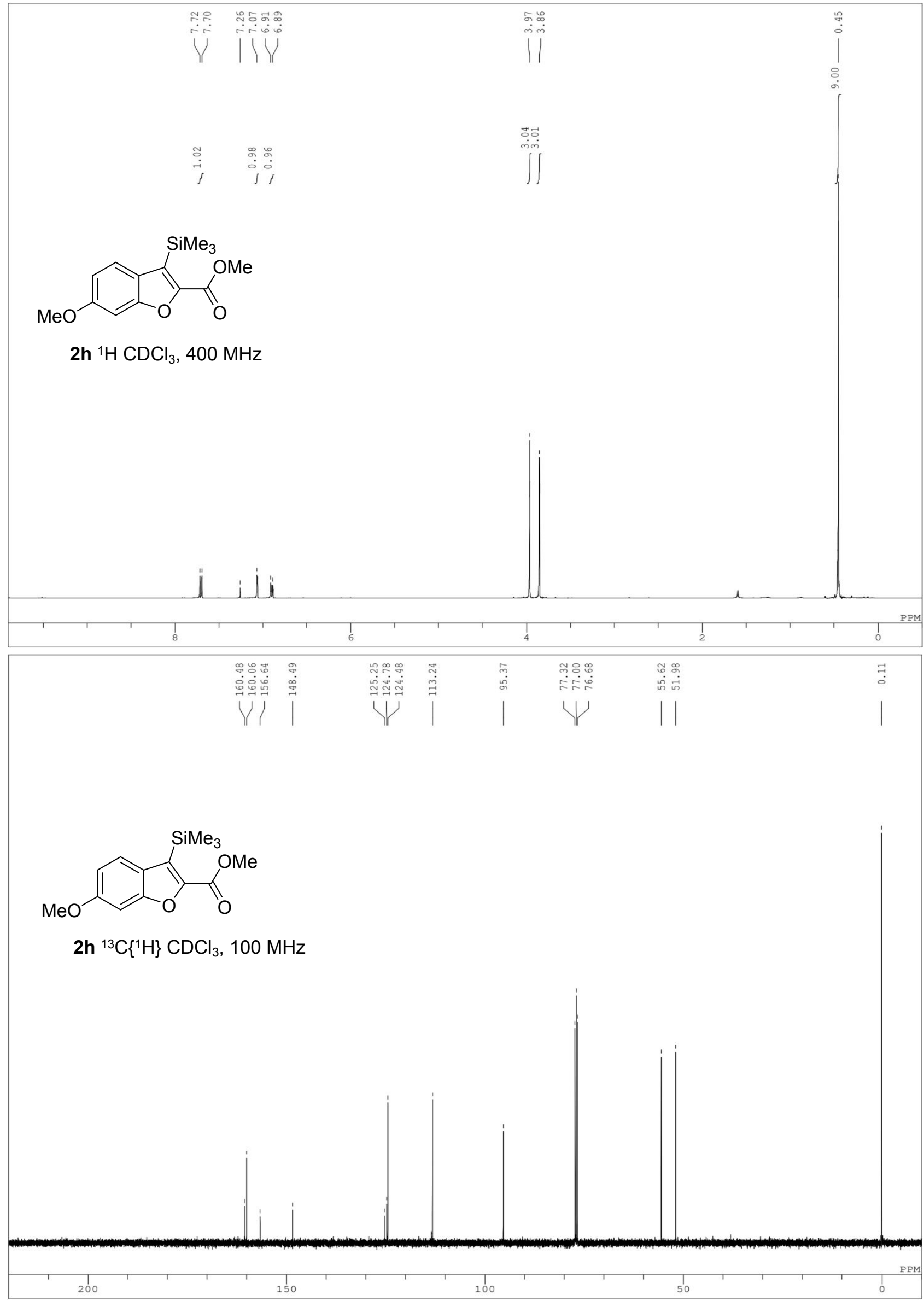




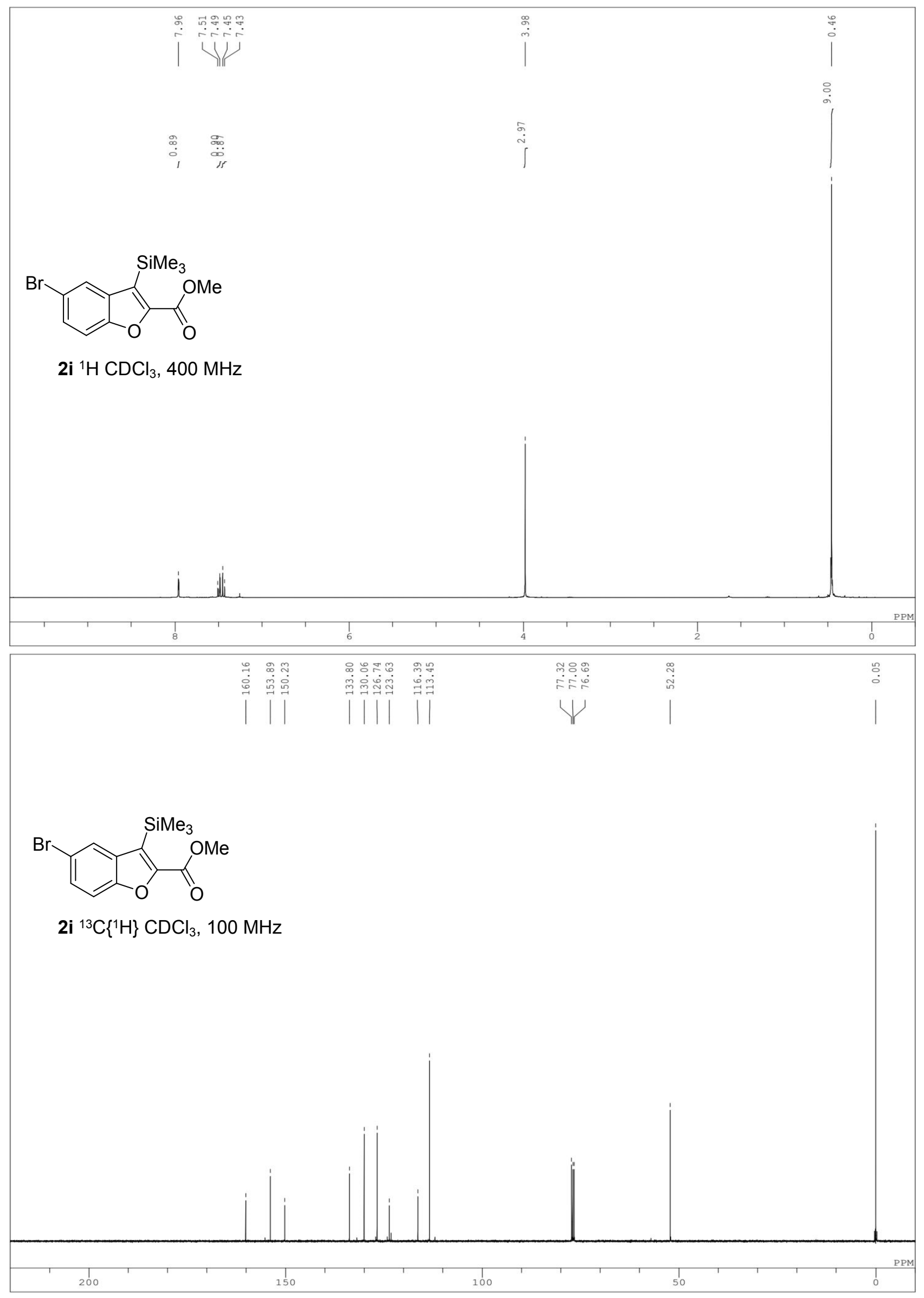

S17 


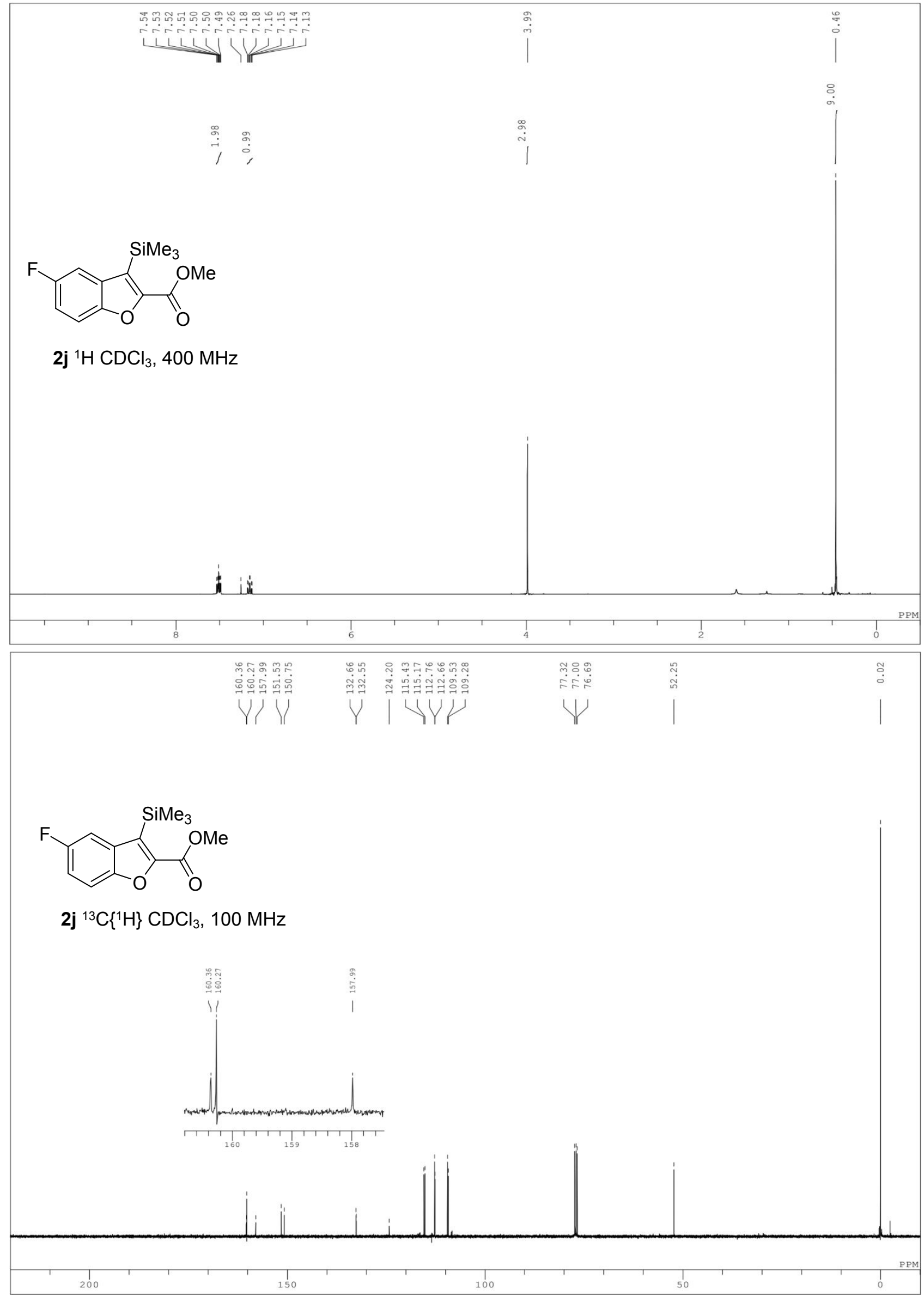




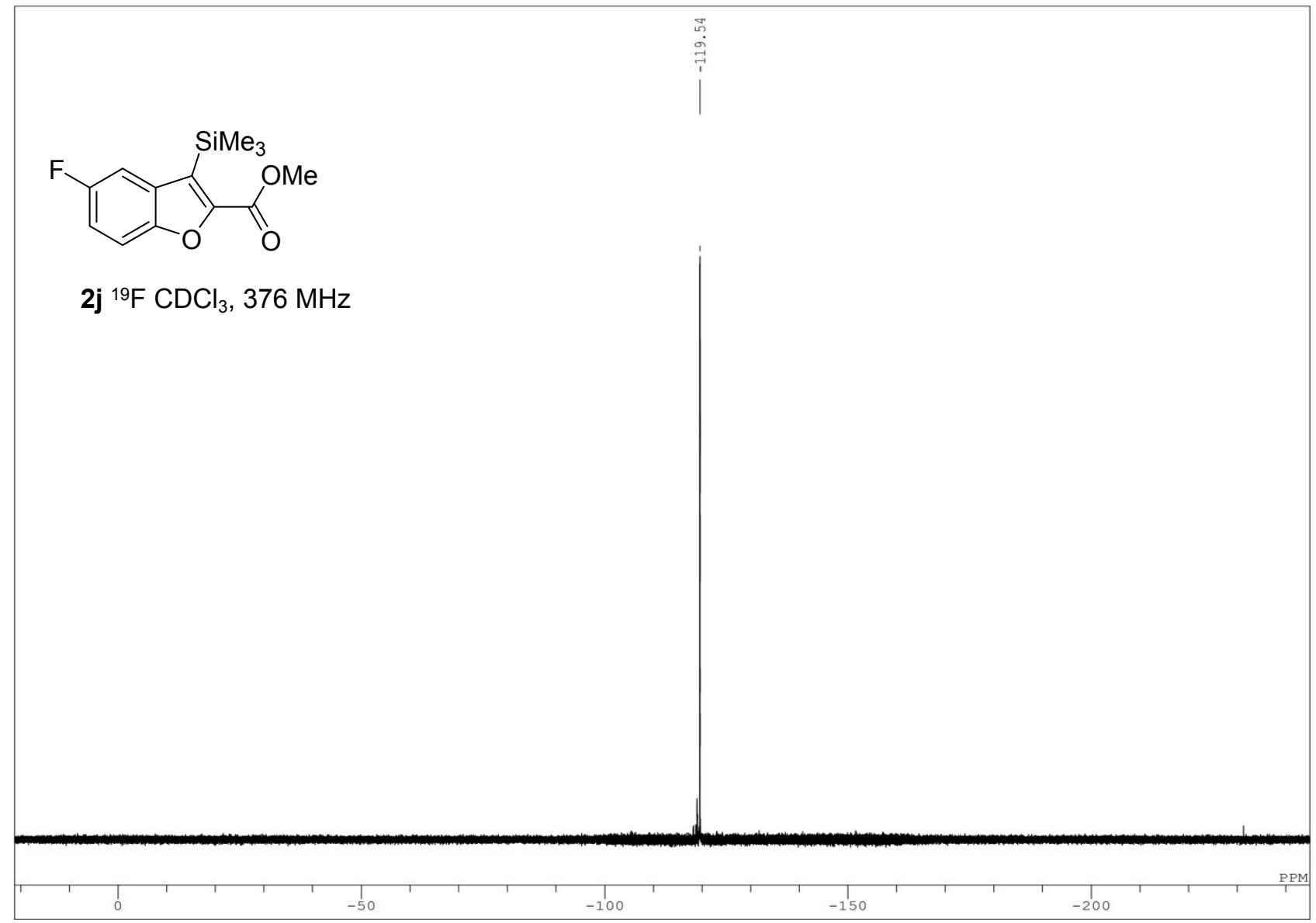




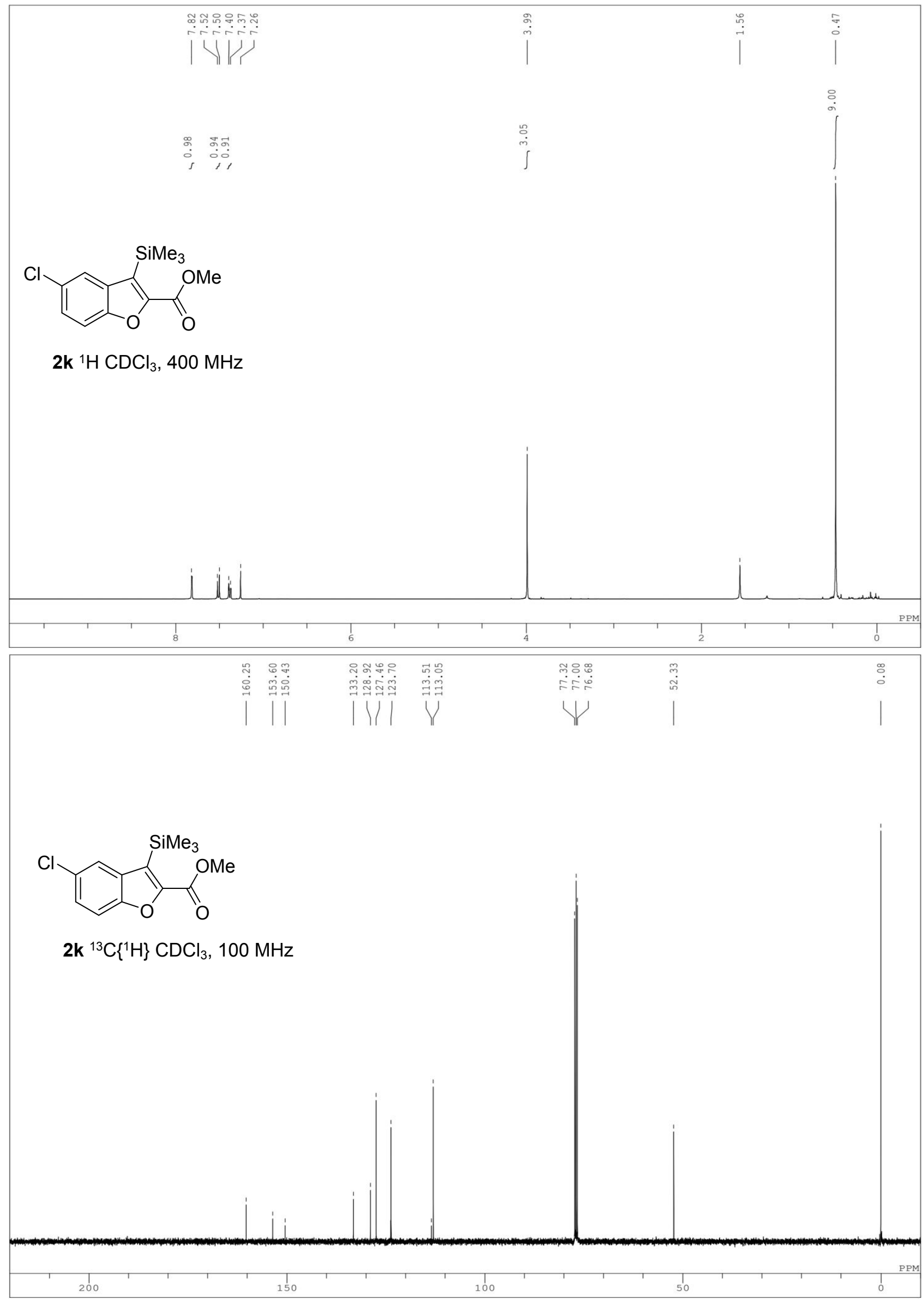




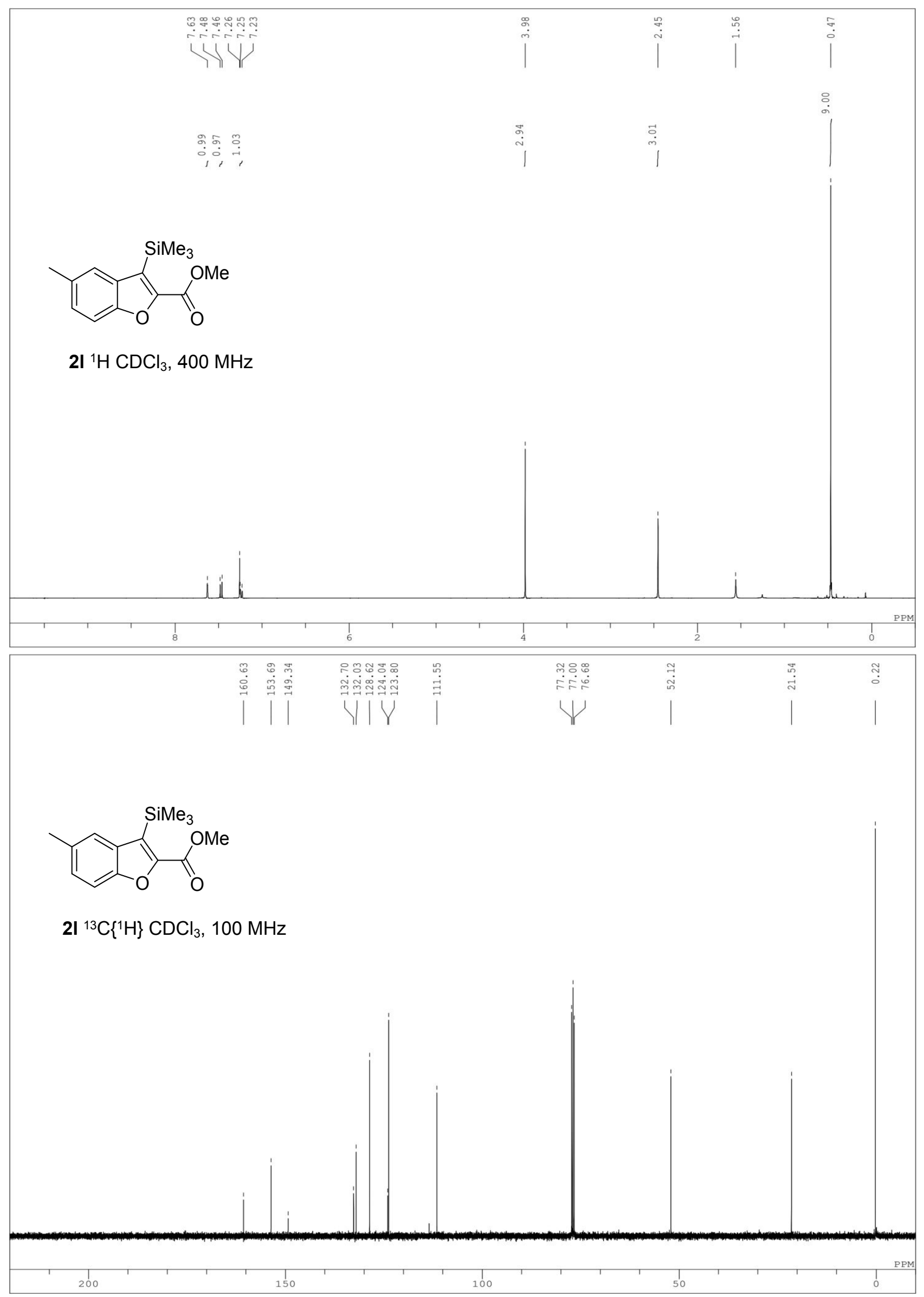

S21 


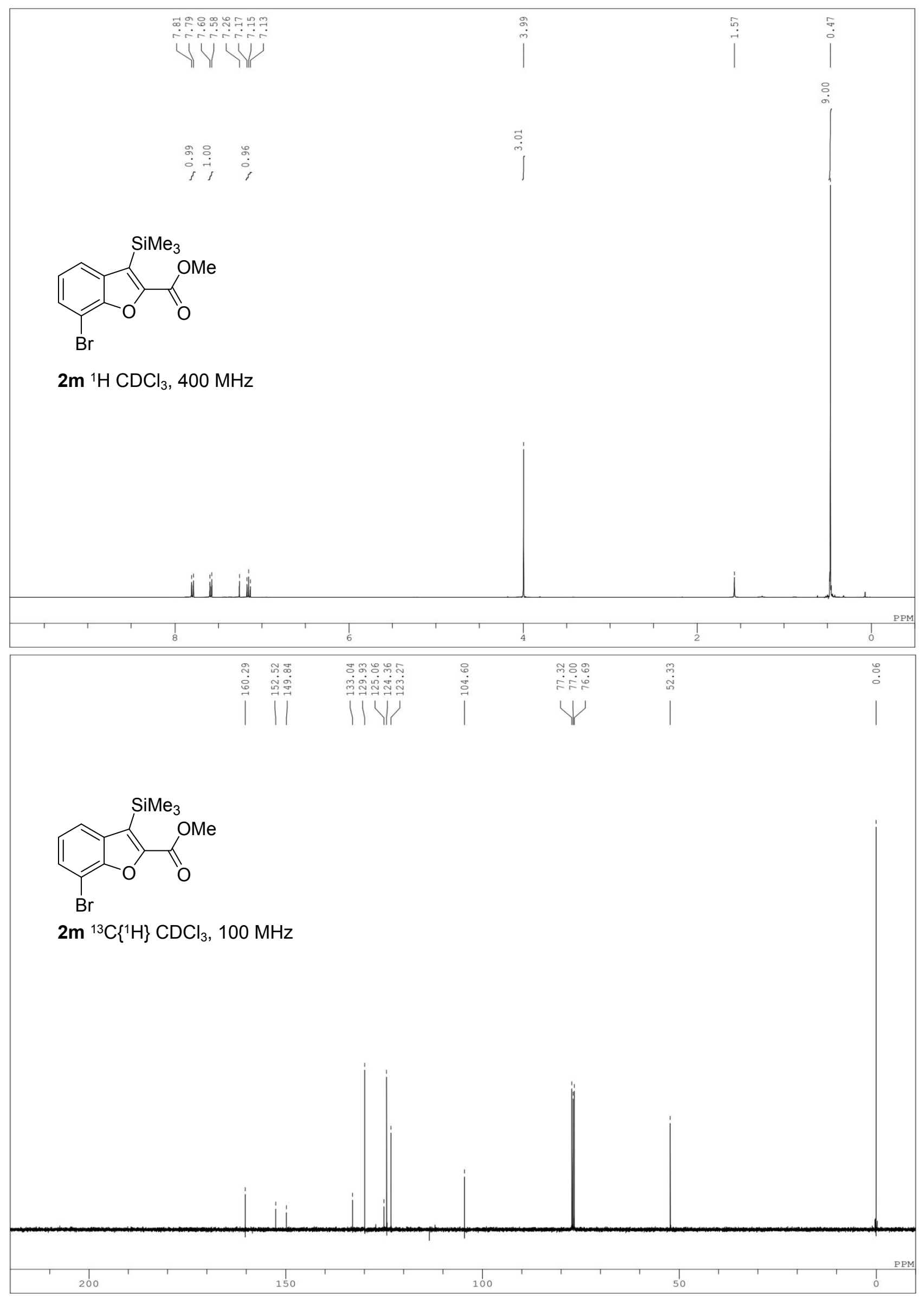

S22 


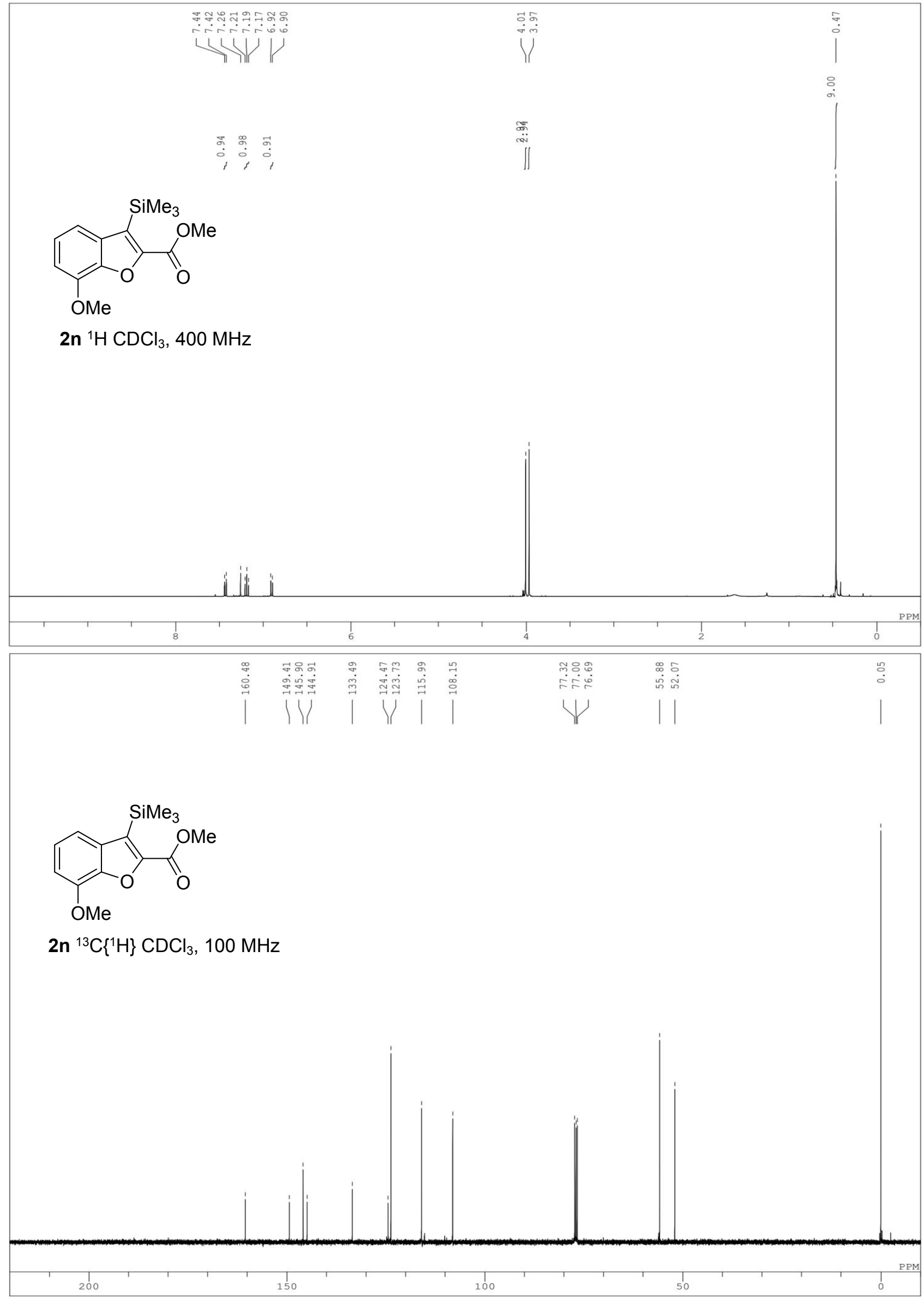




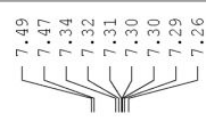

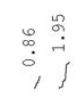

2o ${ }^{1} \mathrm{H} \mathrm{CDCl}, 400 \mathrm{MHz}$
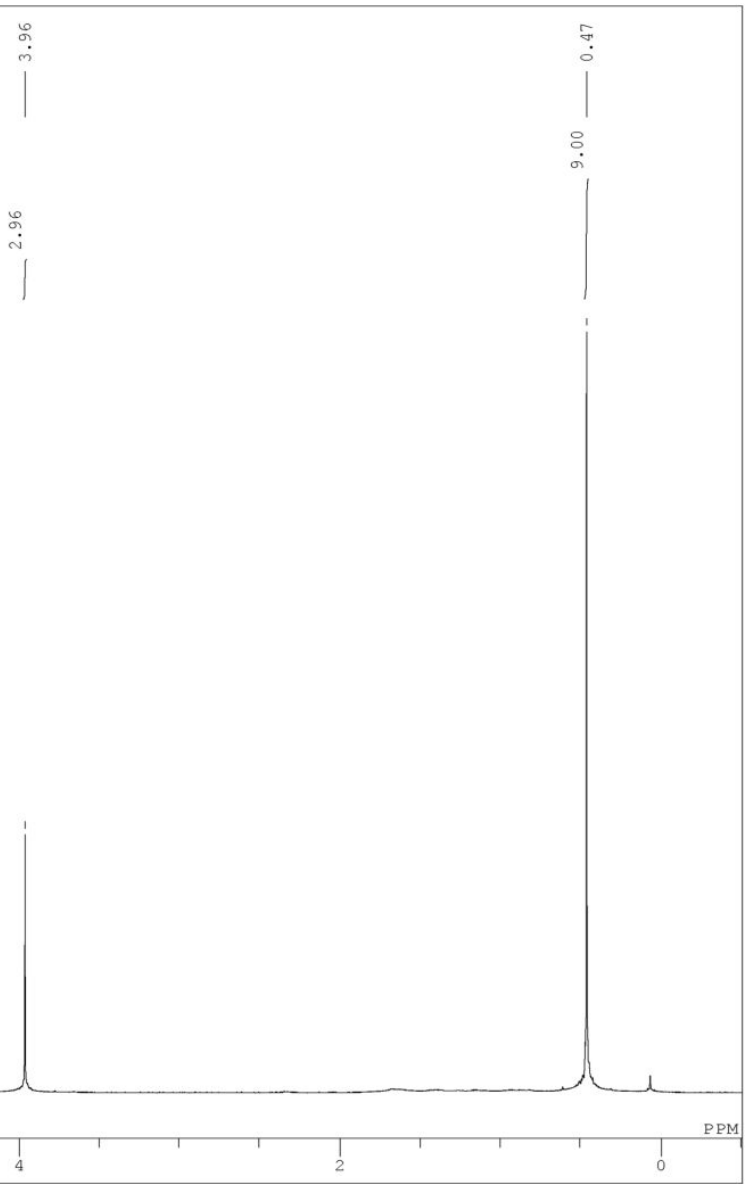

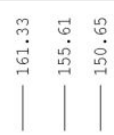

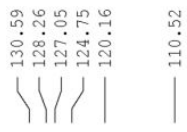

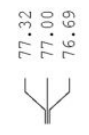

ڤ్<smiles>COC(=O)c1oc2cccc(Cl)c2c1[SiH3]O</smiles>

2o ${ }^{13} \mathrm{C}\left\{{ }^{1} \mathrm{H}\right\} \mathrm{CDCl}_{3}, 100 \mathrm{MHz}$

S24 


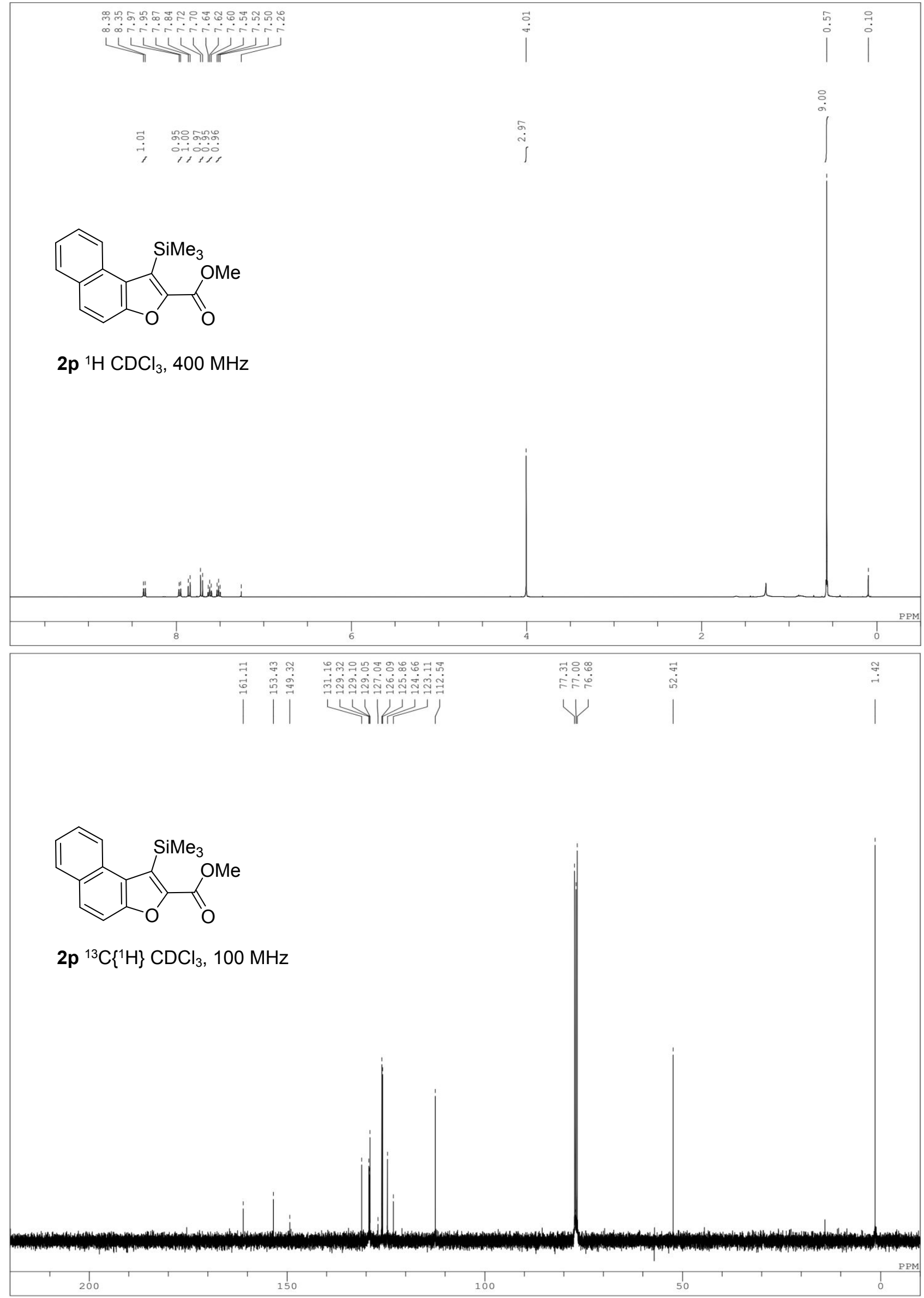




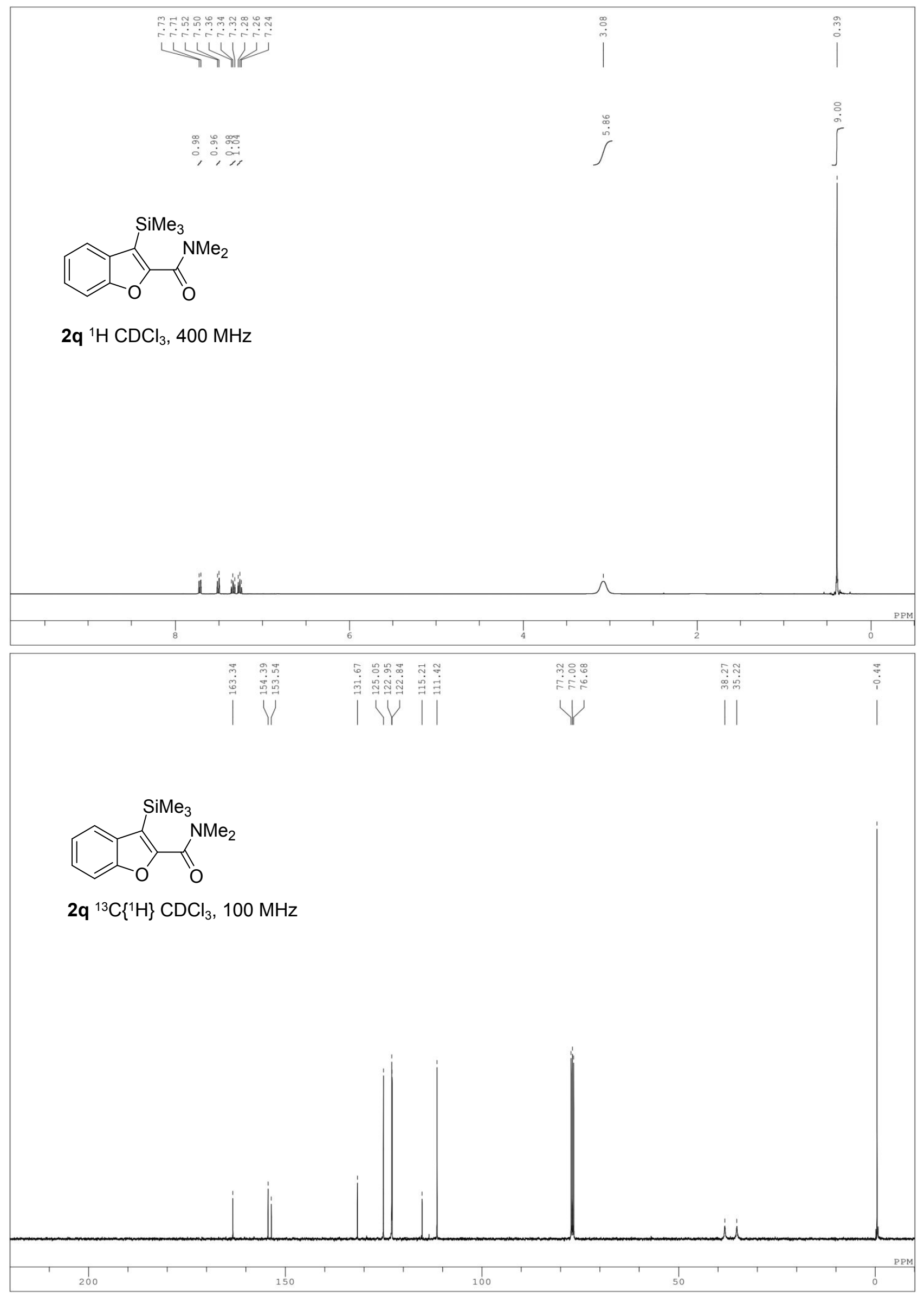

S26 


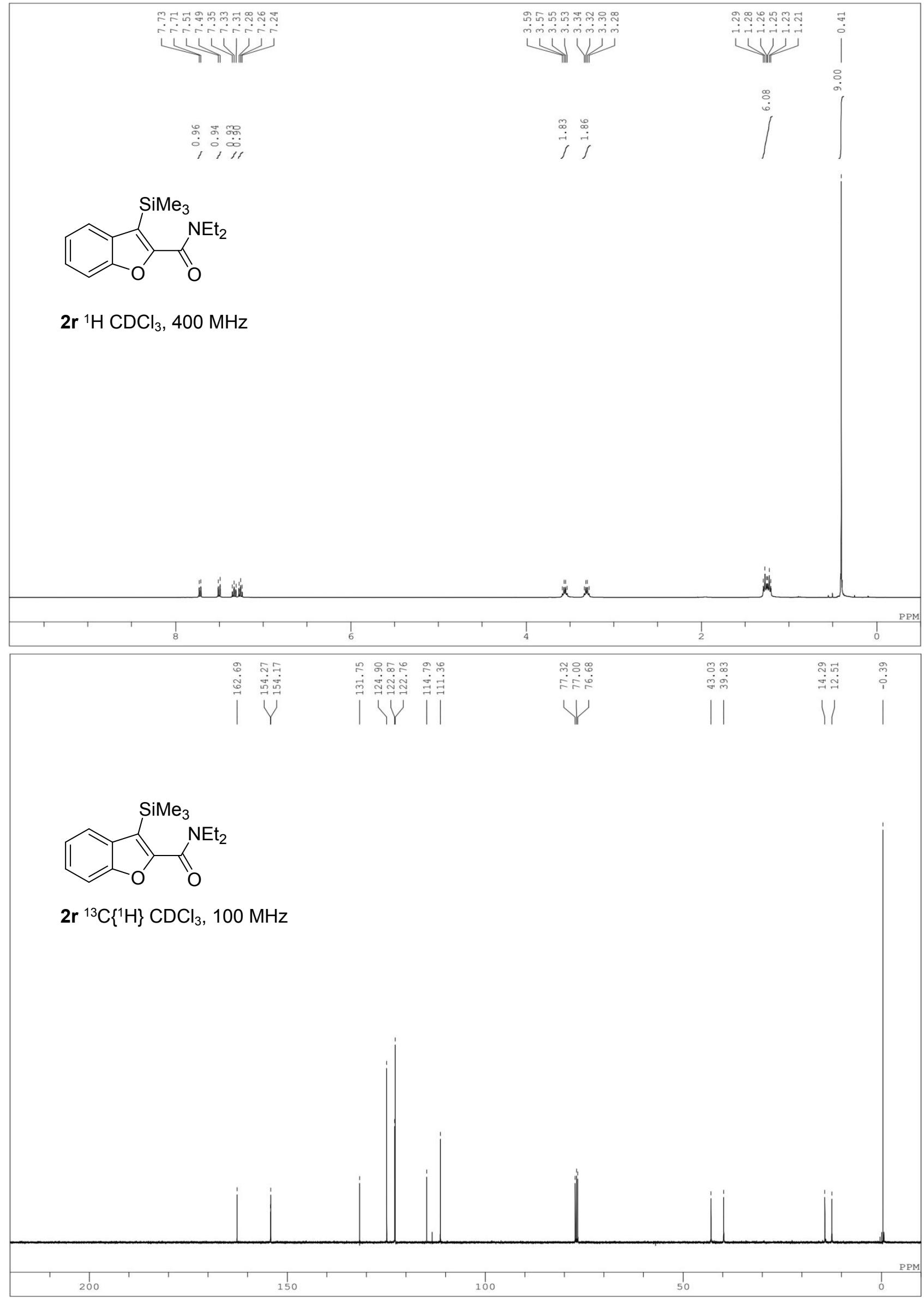




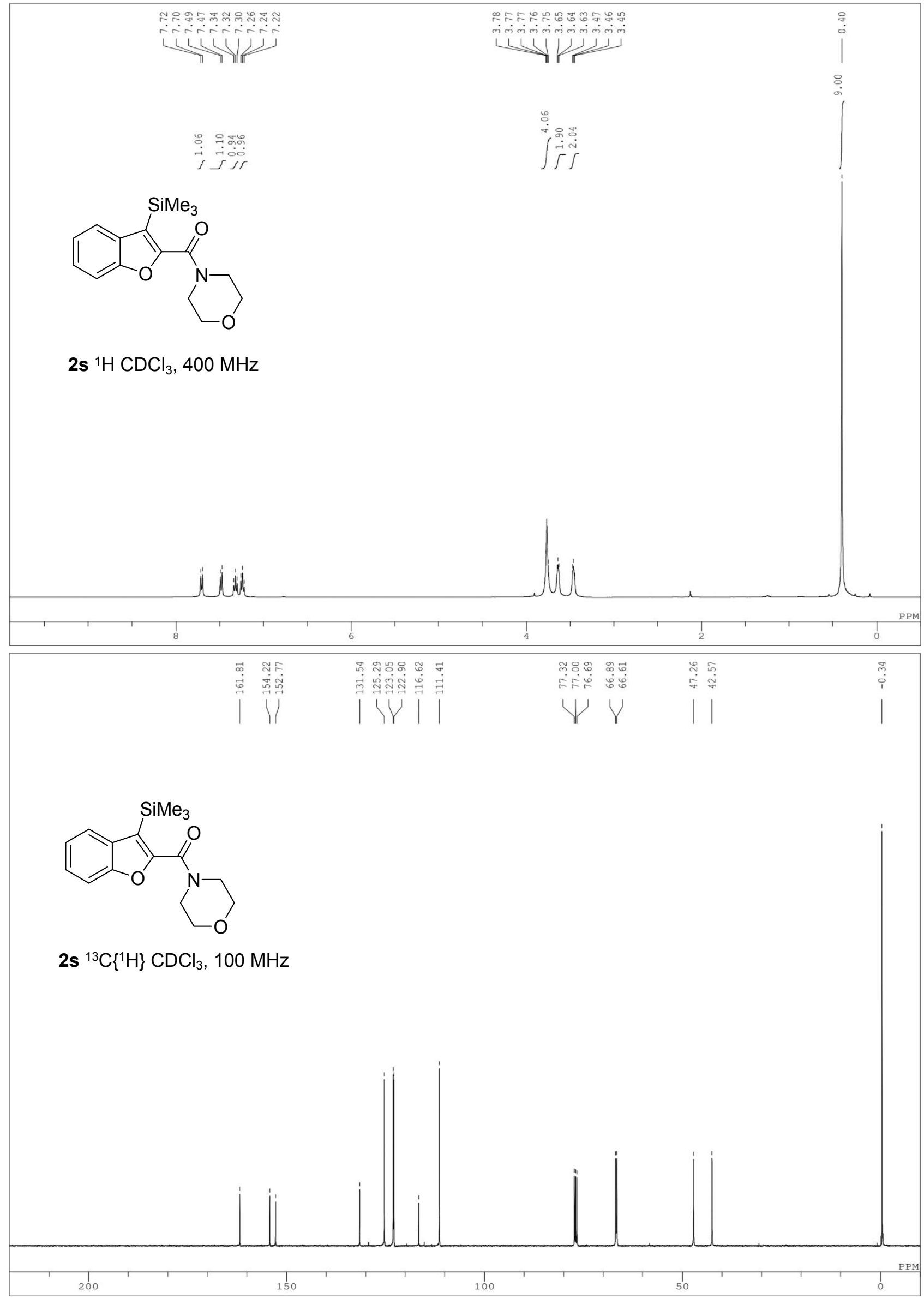




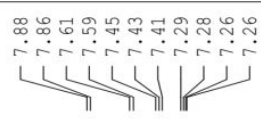

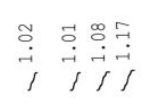

2t ${ }^{1} \mathrm{H} \mathrm{CDCl}_{3}, 400 \mathrm{MHz}$

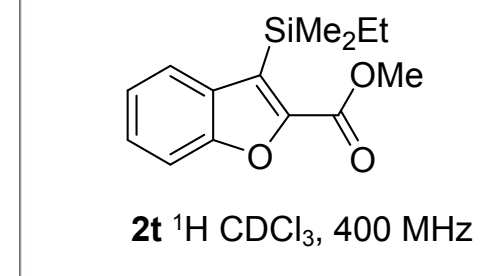

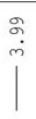

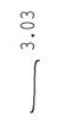
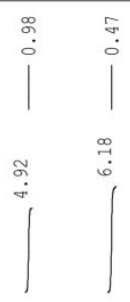
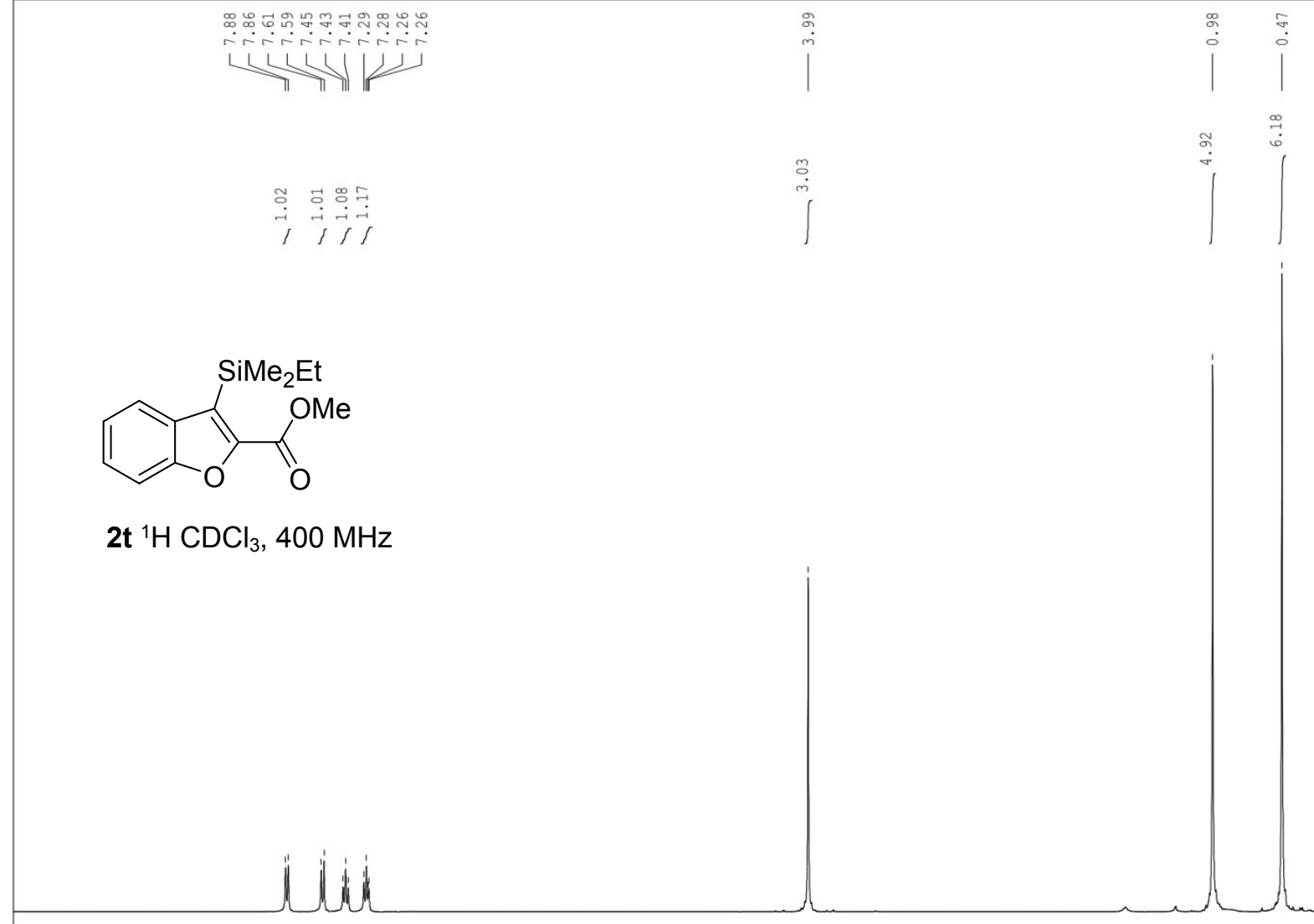

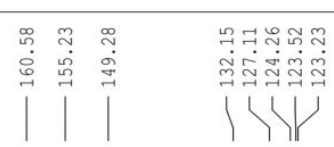

$\stackrel{\circ}{\stackrel{2}{\sharp}}$

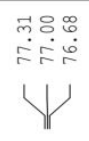
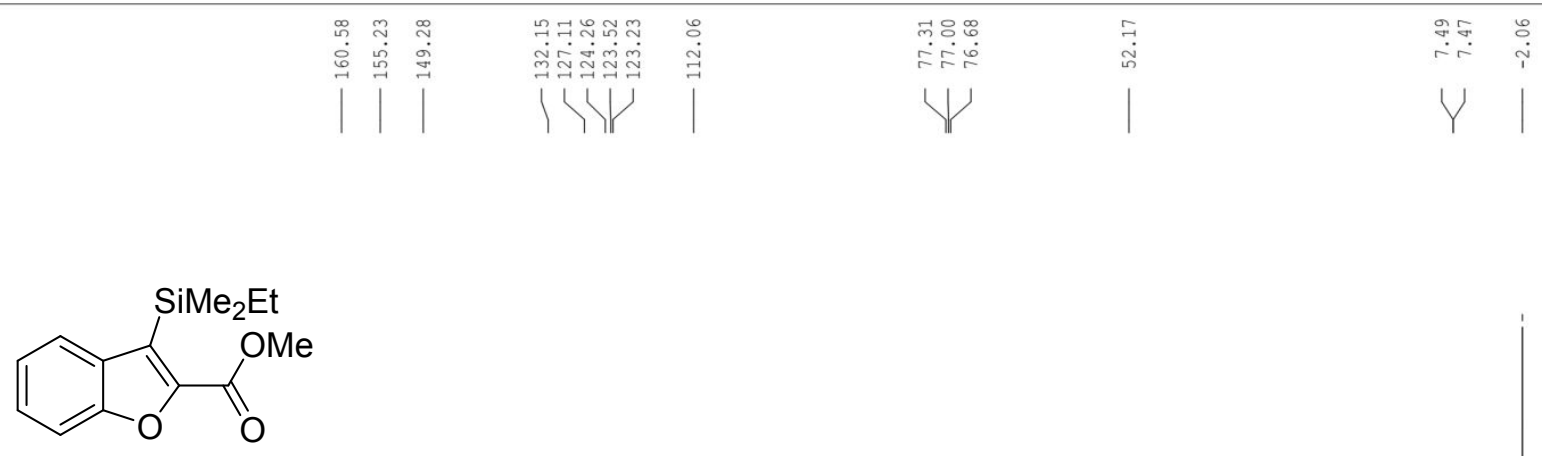

2t ${ }^{13} \mathrm{C}\left\{{ }^{1} \mathrm{H}\right\} \mathrm{CDCl}_{3}, 100 \mathrm{MHz}$

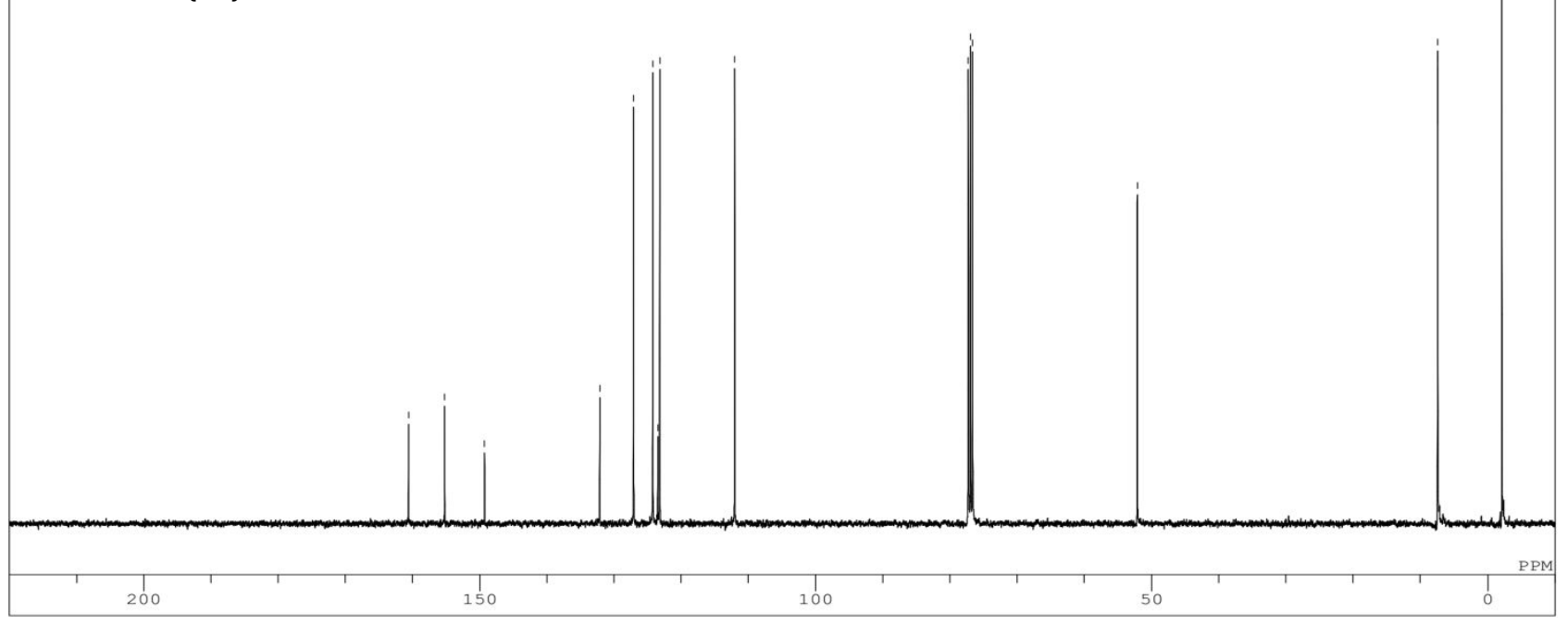

S29 


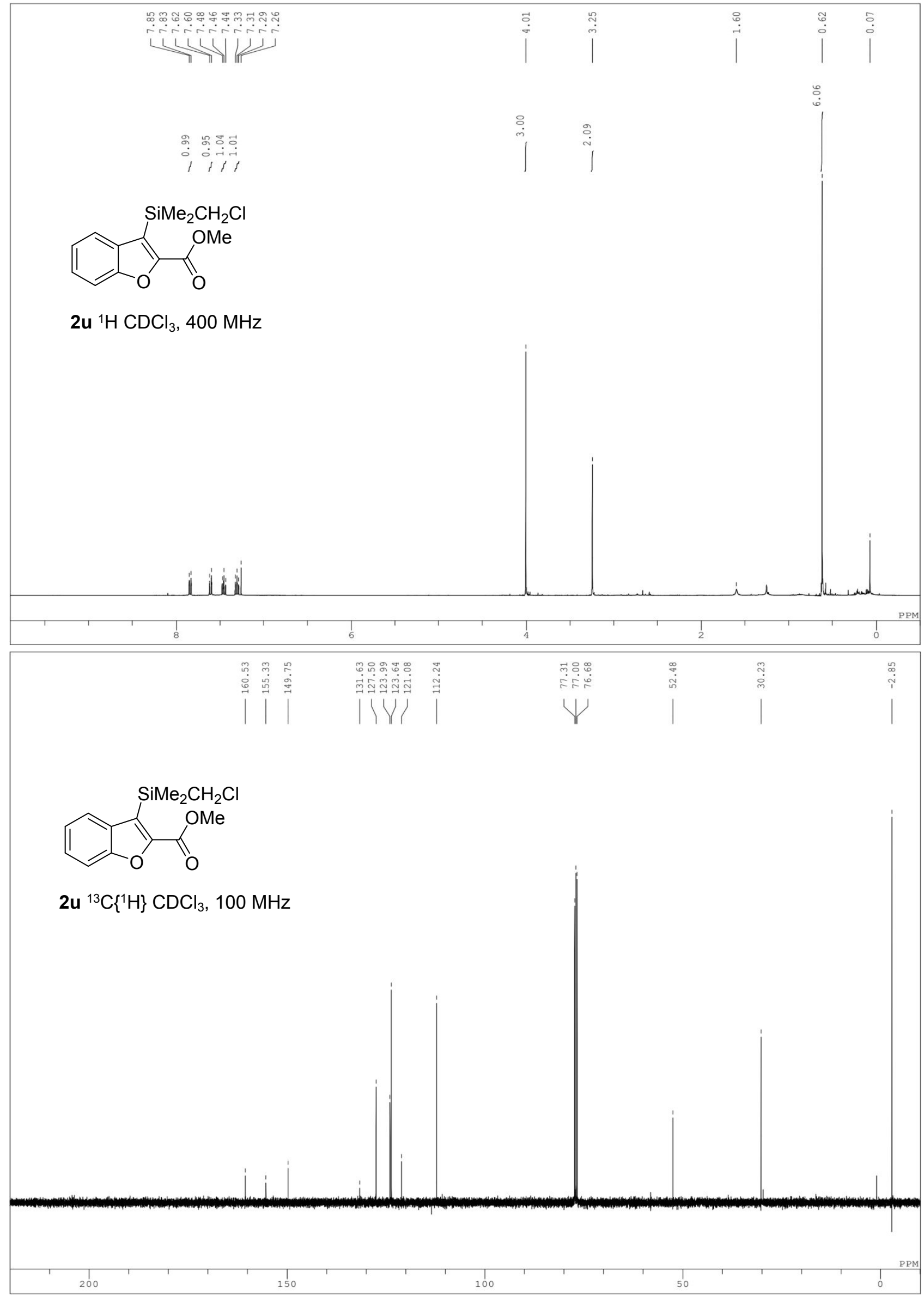




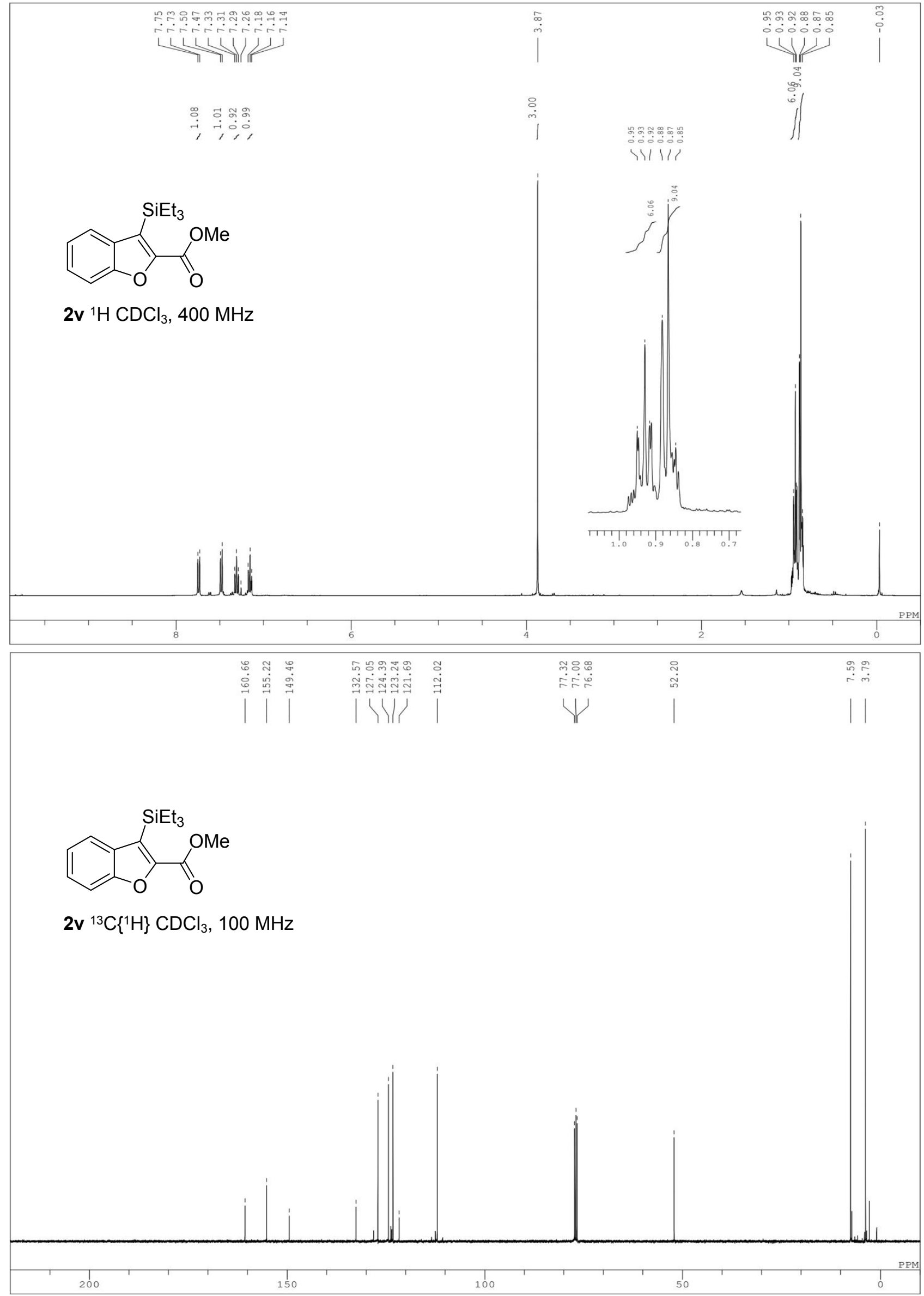




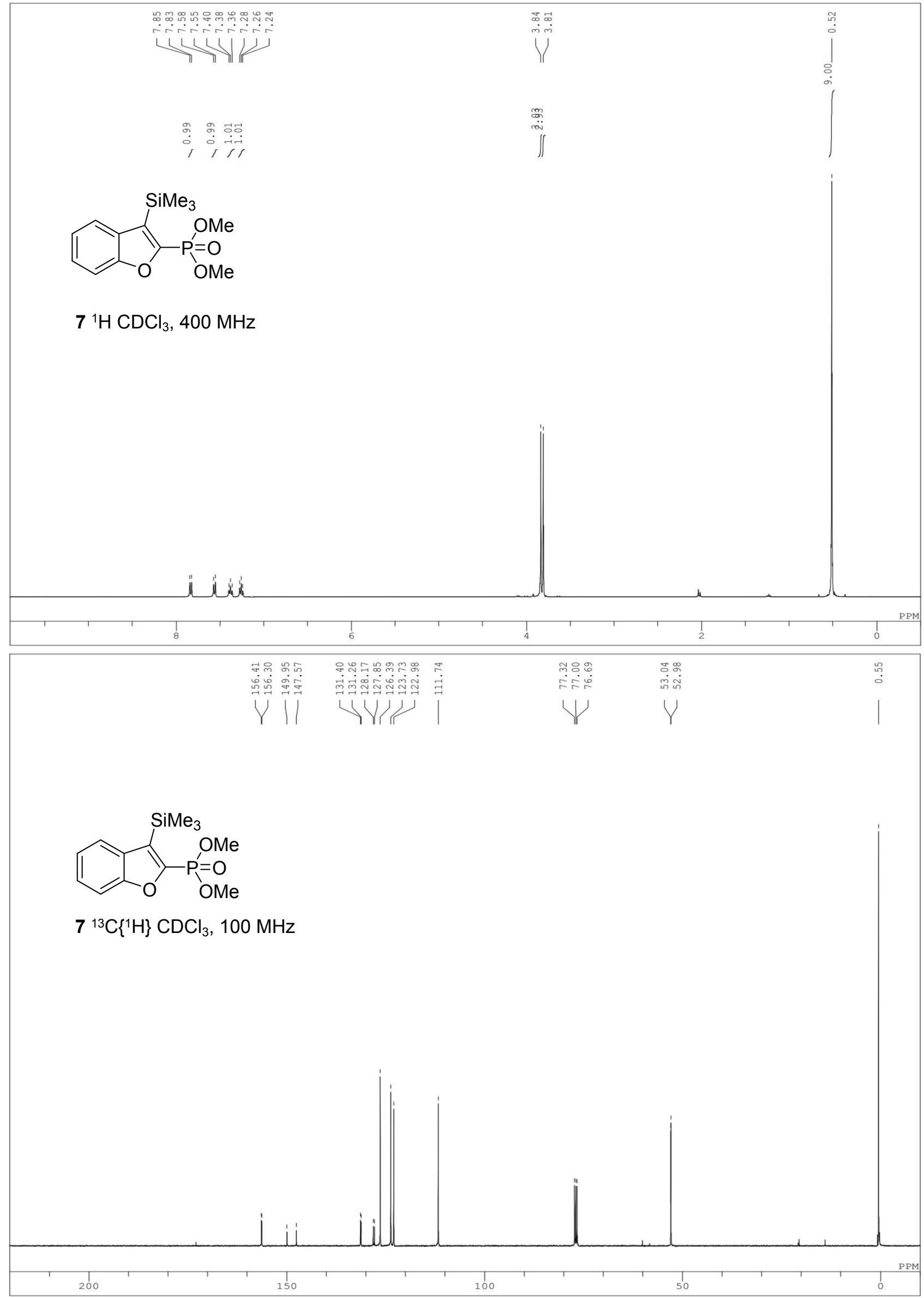




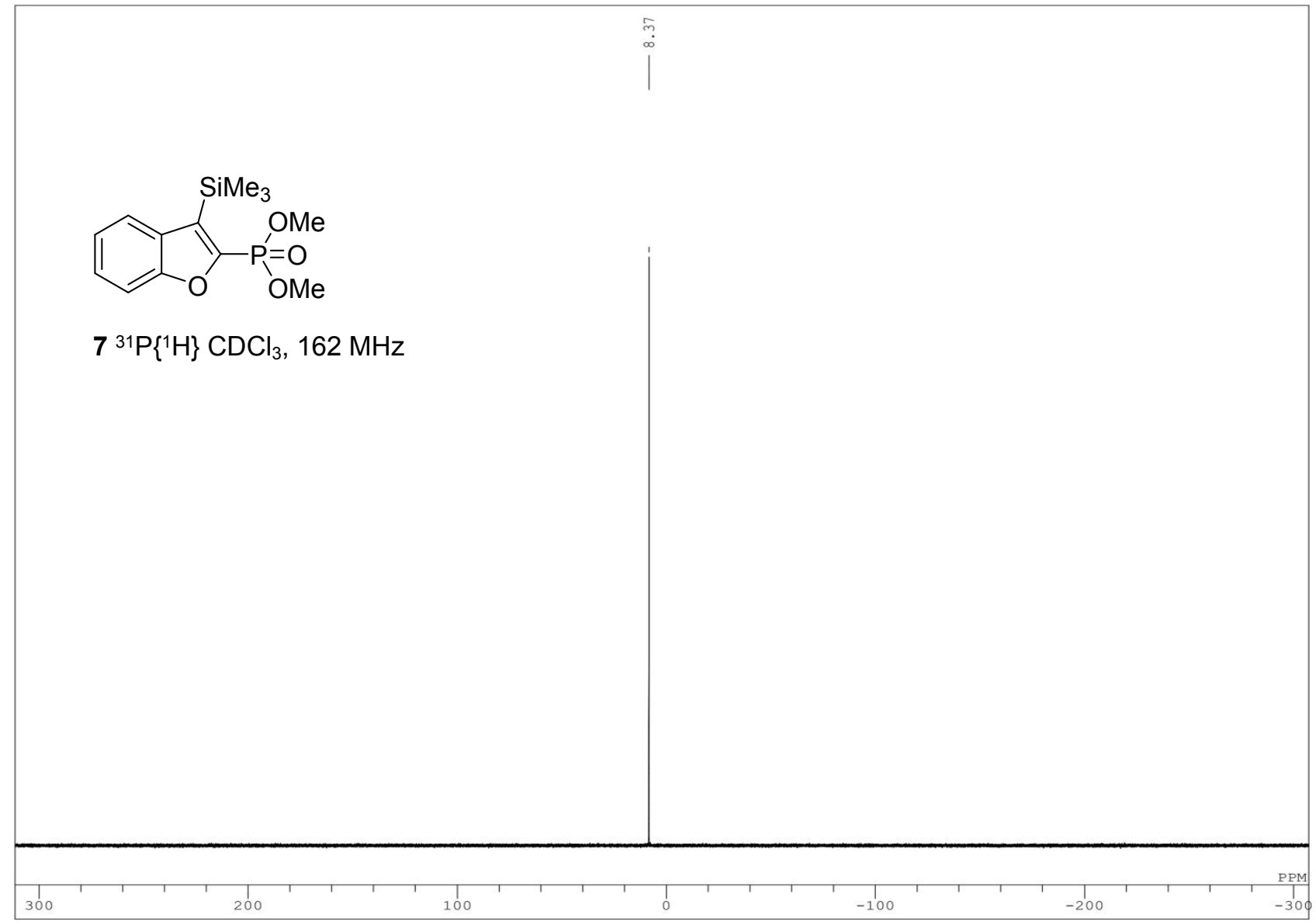




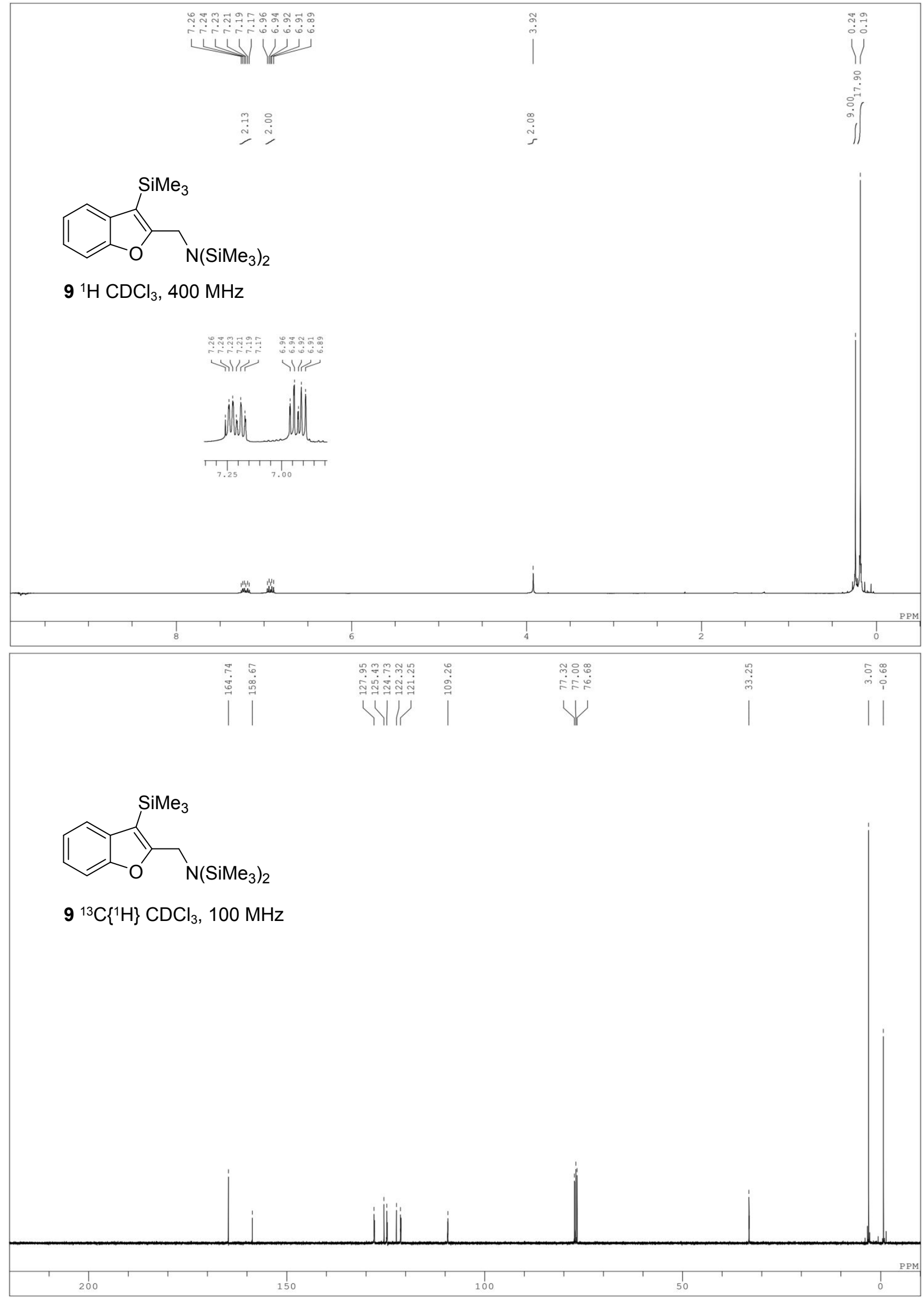




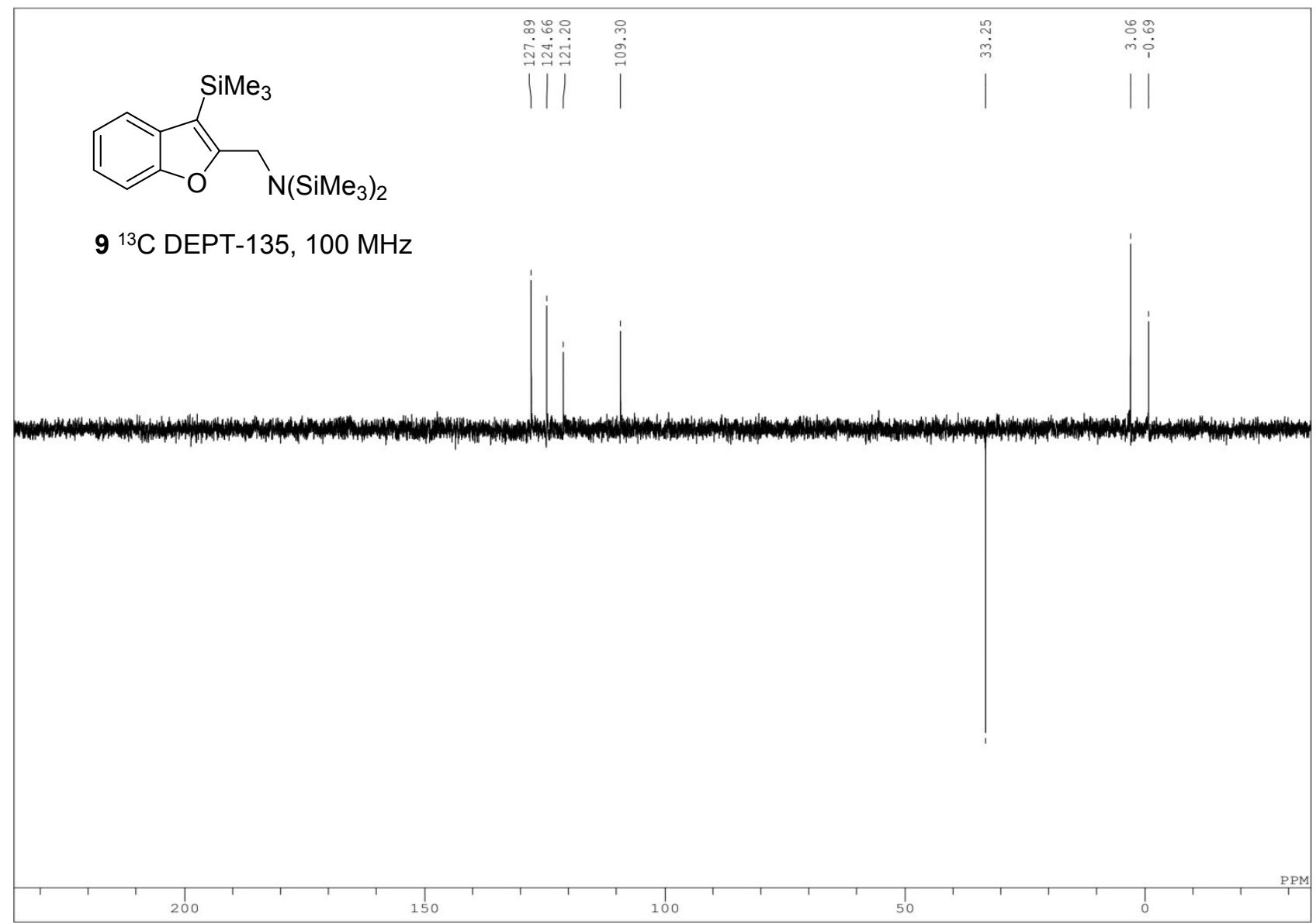




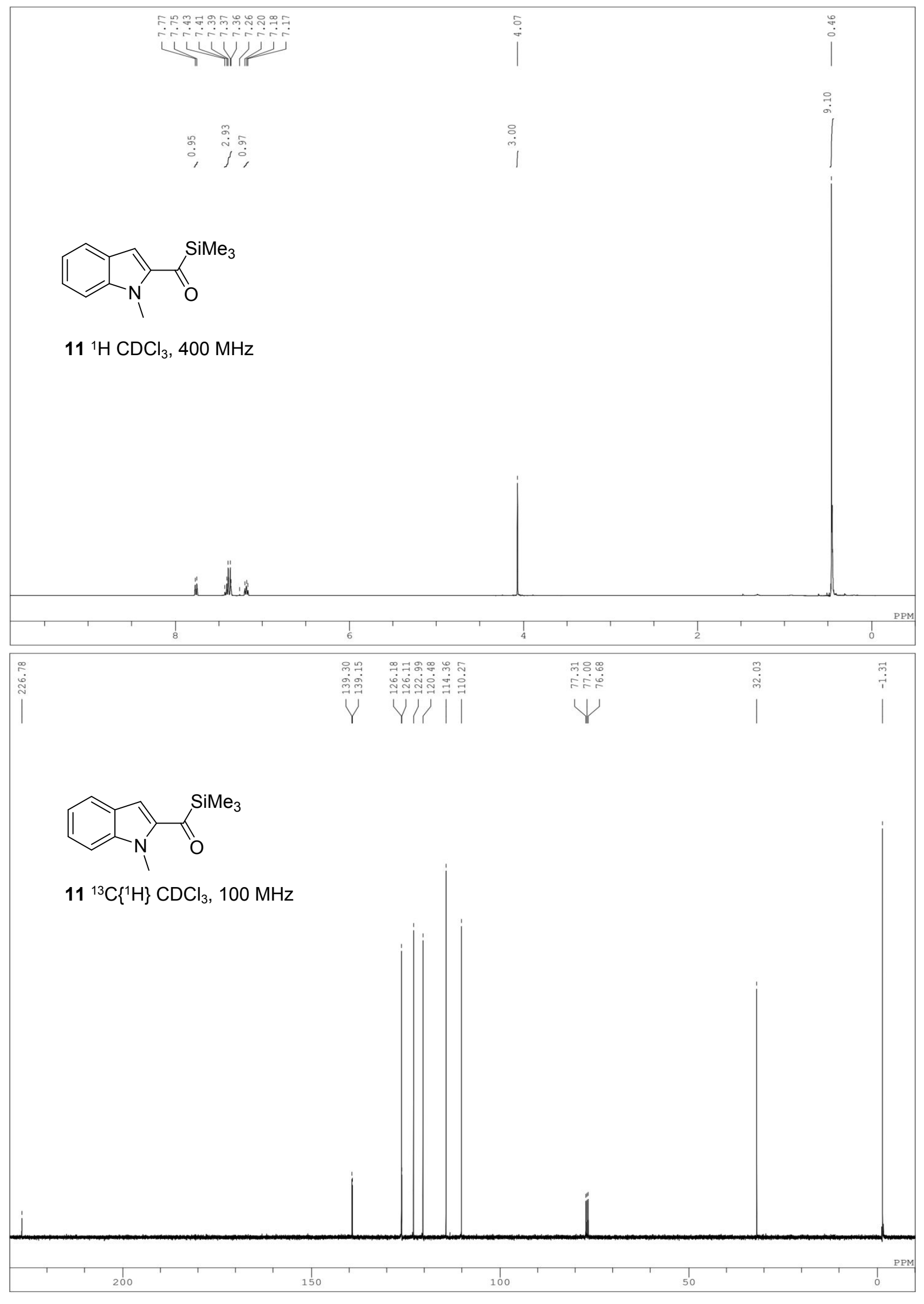

S36 


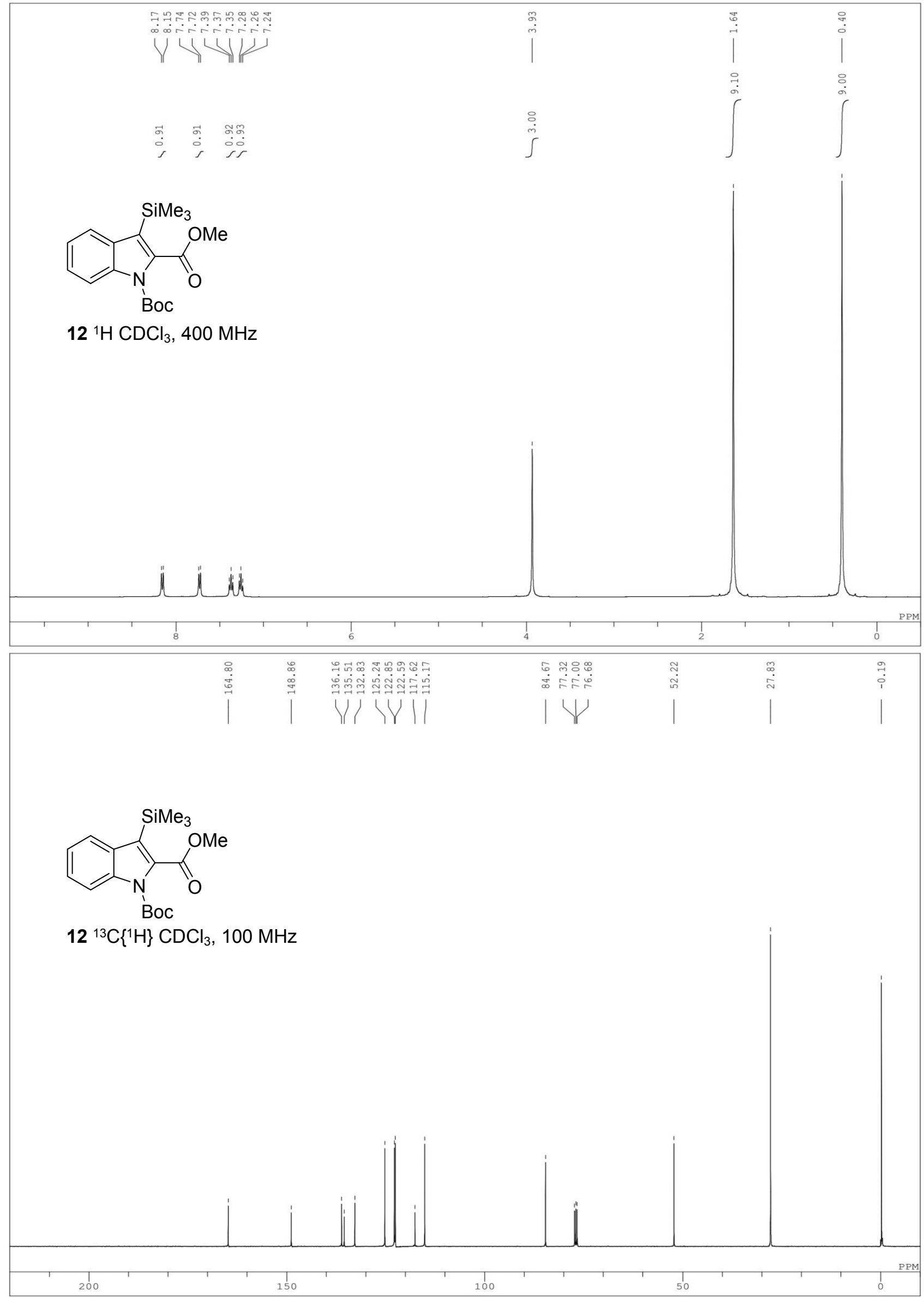



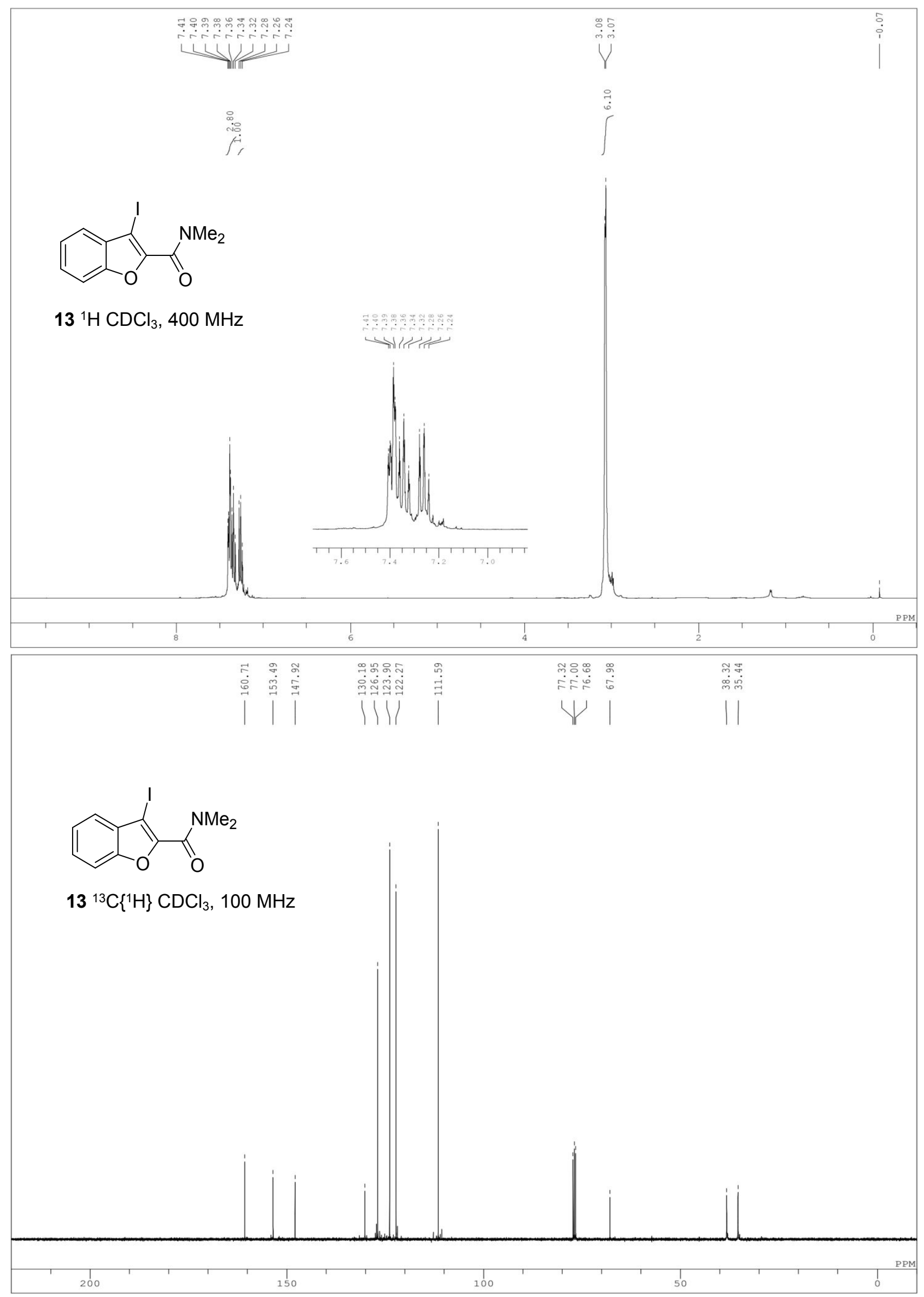

S38 


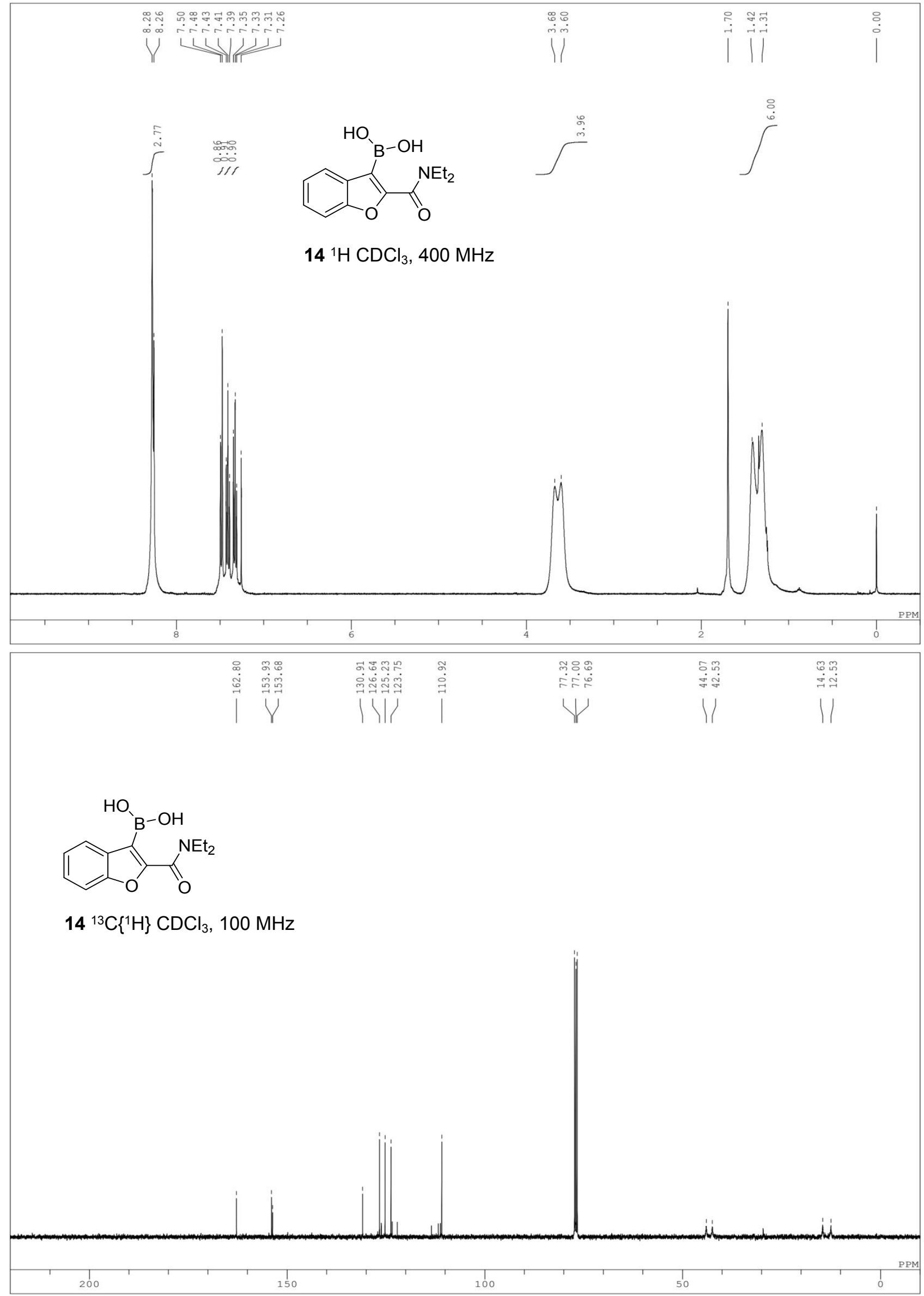




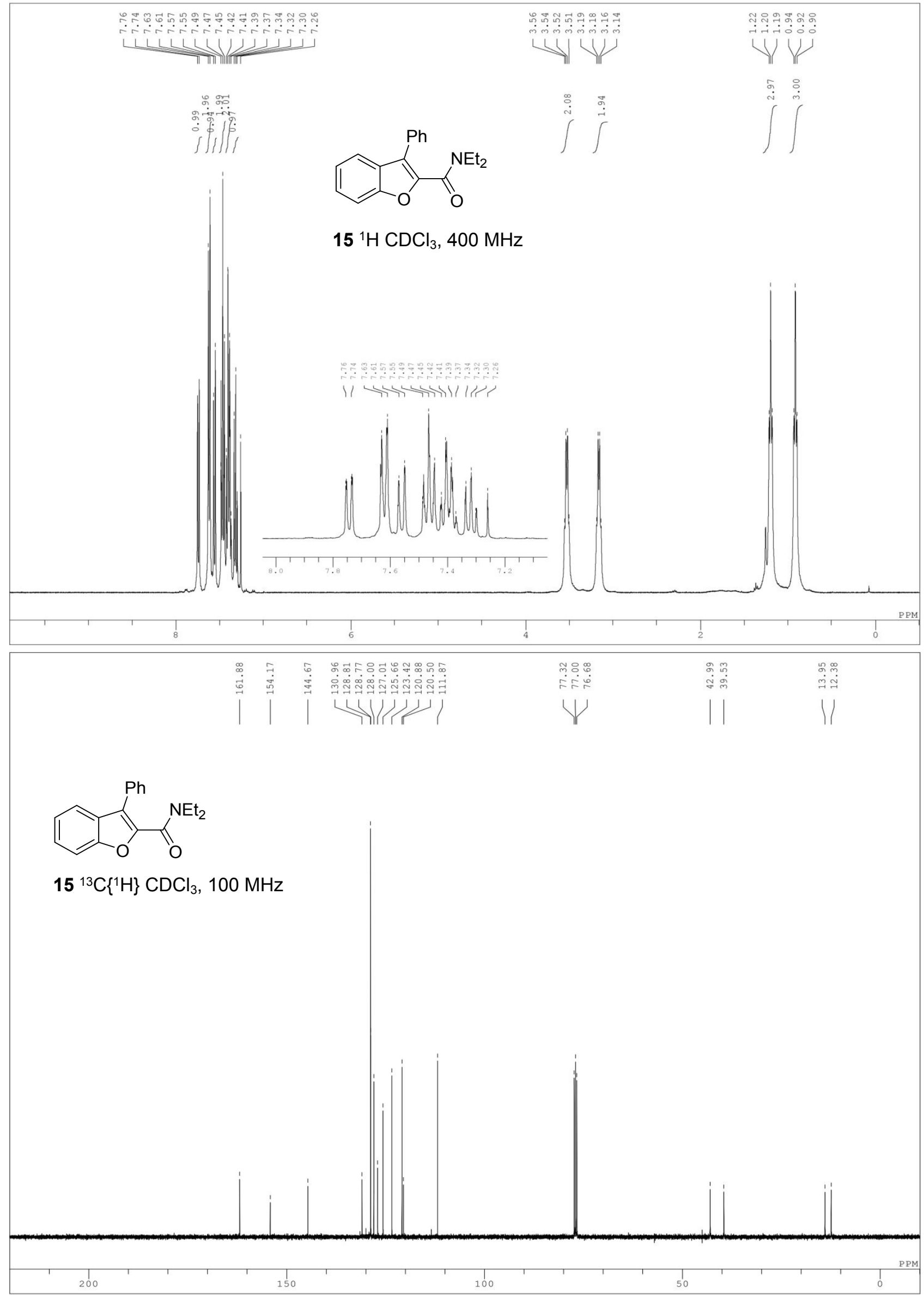




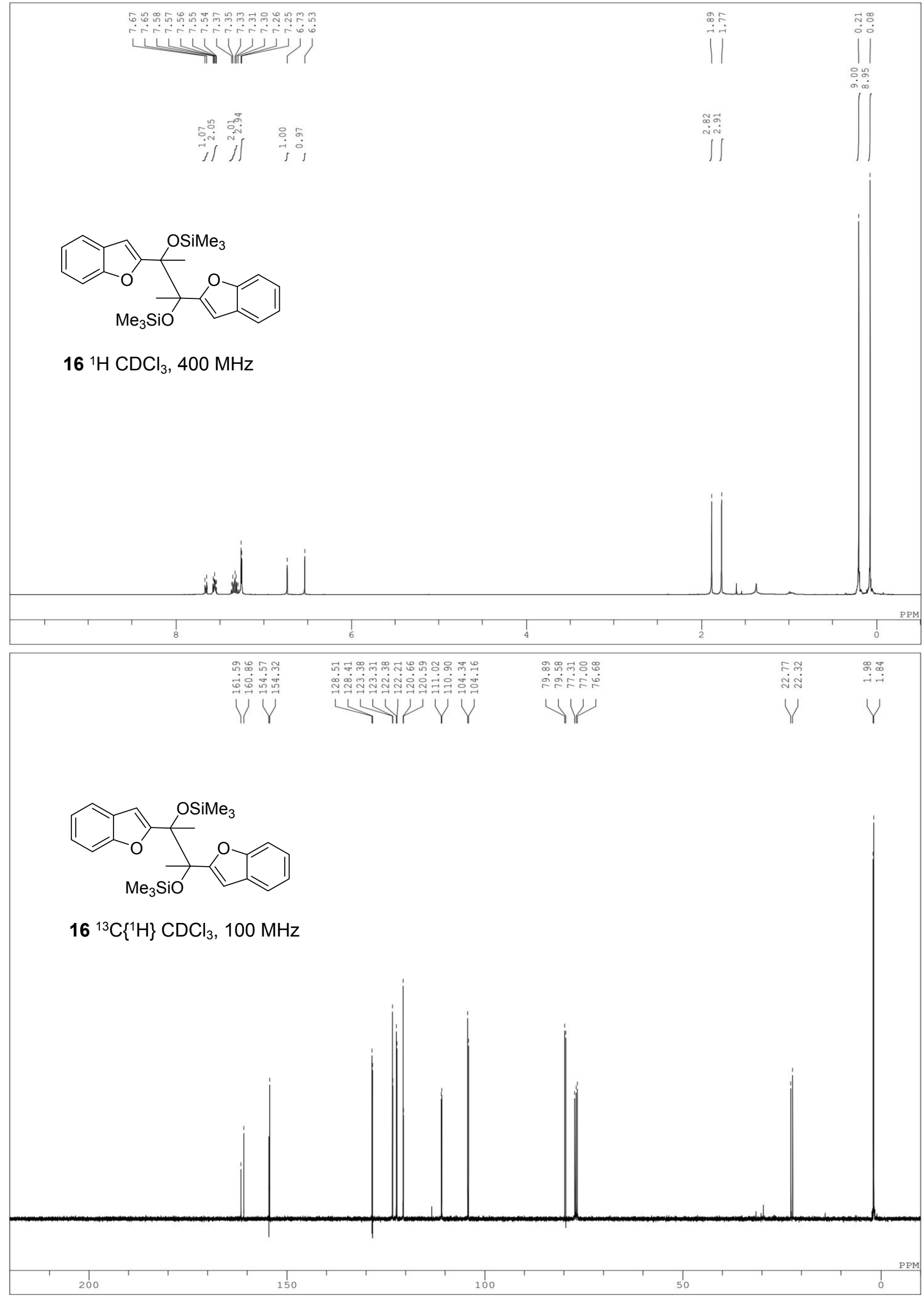

